\title{
Small-molecule modulators of the ATPase VCP/p97 affect specific p97 cellular functions
}

\author{
Ainoa Figuerola-Conchas,,,+ , ๆ Jacques Saarbach,, , §, ๆ Jean-Pierre Daguer,, , $\S$ \\ Adeline Cieren, ${ }^{\dagger}, \ddagger$, Sofia Barluenga,, , $\S$ Nicolas Winssinger,,,$\neq, \S$ Monica Gotta ${ }^{*},+, \ddagger$ \\ † Department of Cell Physiology and Metabolism, University of Geneva, 1211 Geneva 4, Switzerland \\ $\ddagger$ Swiss National Centre for Competence in Research in Chemical Biology, University of Geneva, \\ Geneva, Switzerland \\ $\S$ Department of Organic Chemistry, University of Geneva, 1211 Geneva 4, Switzerland
}

\section{Supplementary Information}

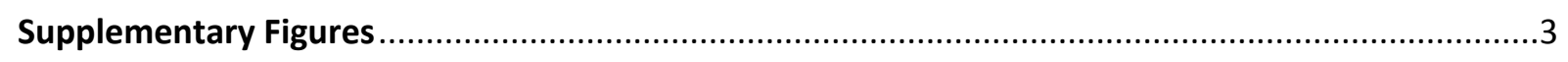

Supplementary Figure S1: Heat map of fluorescence intensity ....................................................

Supplementary Figure S2: Silver nitrate stain of HEK 293 lysates pulldown.....................................3

Supplementary Figure S3: Kinetics of UbG76V-GFP degradation for NW1028 and NW1030............4

Supplementary Figure S4: SPR affinity measurement of NW1028 and NW1030 on p97(E578Q) a D2

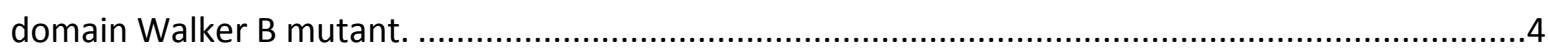

Supplementary Figure S5: Schematic summary of photocrosslinking experiment. ..........................5

Supplementary Figure S6: NW1028 competes the photo-labelling of p97 ND1L. ...........................6

Supplementary Figure S7: MALDIs of photocrosslinking and tryptic digest pulldown of p97 ND1L...7

Supplementary Figure S8: High resolution images from the docking of NW1028 on ND1L monomer

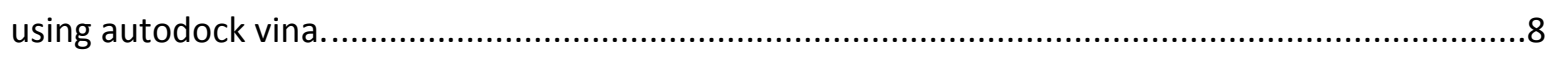

Supplementary Figure S9: Docking of NW1030 on ND1L monomer using autodock vina.................9

Supplementary Figure S10: MTT assay of NW1028 and NW1030 on HeLa cells............................10

Supplementary Figure S11:Enlarged high resolution image of Figure 5B. ....................................11

Supplementary Figure S12: NW1028 and NW1030 do not affect mitotic timing. ...........................12

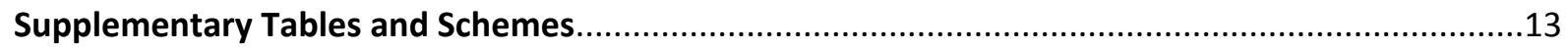

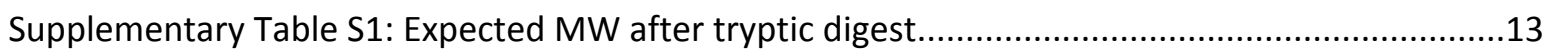

Supplementary Table S2: Peptides identified after tryptic digest ................................................15

Supplementary Table S3: Affinities of the 9 best binding modes determined by autodock vina.....16

Supplementary Table S4: Structure and numbers of compounds used in the paper.......................17

Supplementary Scheme S1: Synthetic scheme of biotinylated compounds. ..................................19

Supplementary Scheme S2: Synthetic scheme of hit compounds. ................................................19

Supplementary Scheme S3: Synthesis of photoaffinity labelling analogue NW1028-PAL-Alk ..........19 
Supplementary Scheme S4: Synthesis of Cy3-DTB linker

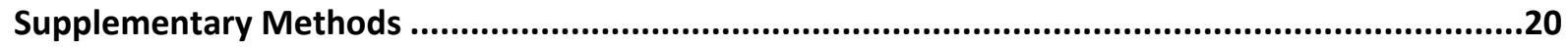

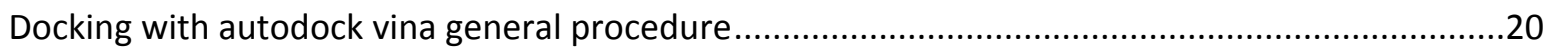

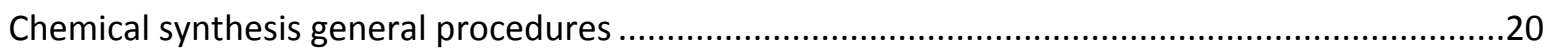

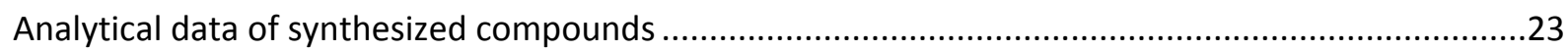




\section{Supplementary Figures}

A.

p97 ND1L $300 \mathrm{nM}+\mathrm{ADP} 2 \mathrm{mM}$

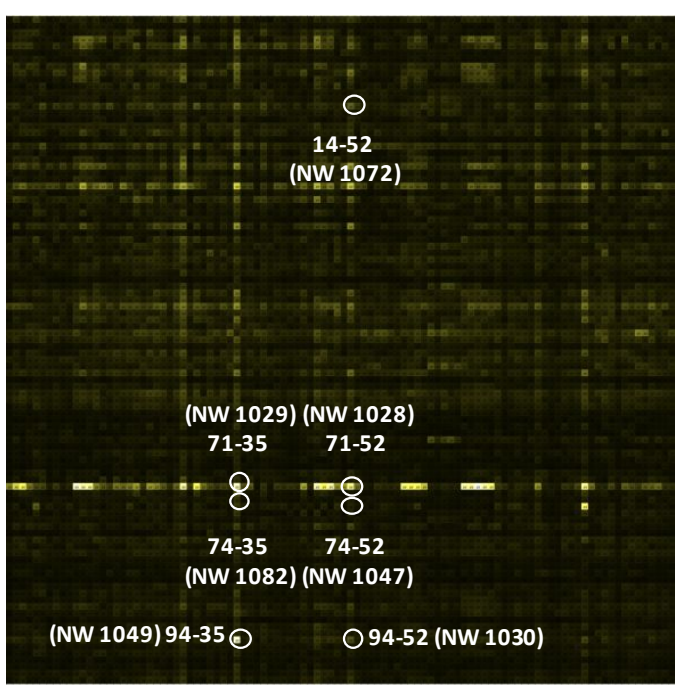

B. p97 ND1L $300 \mathrm{nM}+$ ATP $\gamma \mathrm{S} 2 \mathrm{mM}$

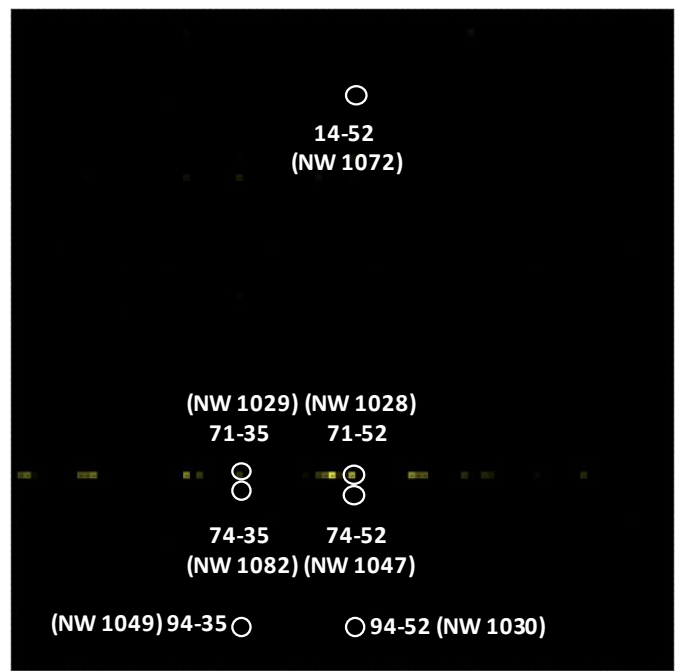

Supplementary Figure S1: Heat map of fluorescence intensity (Cy5 channel) for the screen of a 10000 membered DNA-PNA encoded library. The fluorescence is quantified and represented on a $100 \times 100$ diagram with codon 1 on the horizontal axis and codon 2 on the vertical axis. The fluorescence intensities are the median of 4 values.

A

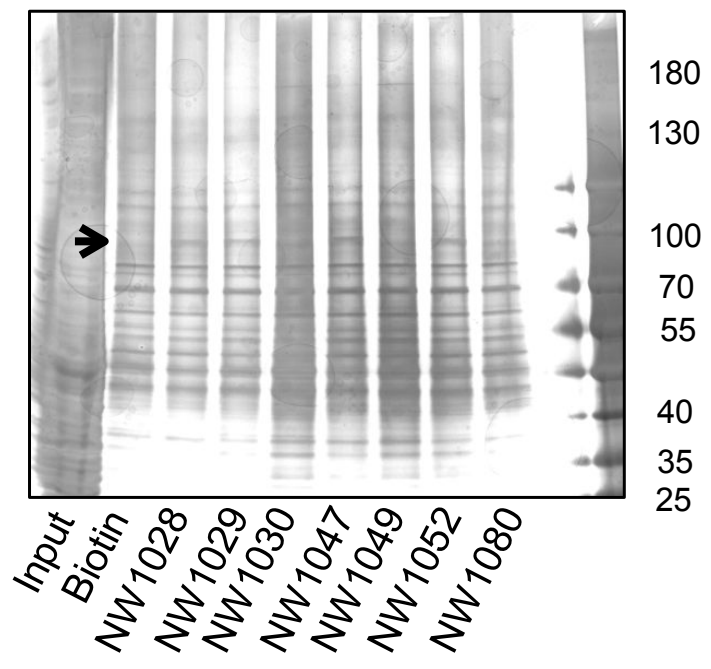
B $\quad 2 \mathrm{mMADP}$

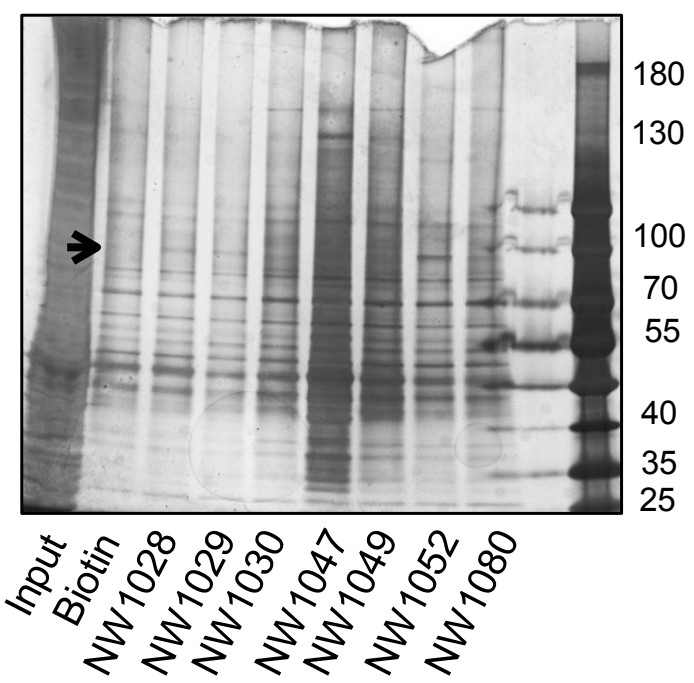

Supplementary Figure S2: Silver nitrate stain of HEK 293 lysates pulldown. (A) with cell lysates only and (B) with addition of 2 mM ADP to the cell lysates. WT p97 is indicated by a black arrow and does not appear in the Biotin negative control pulldown for unspecific interactions with the magnetic beads. Other proteins pulled down by the compounds can correspond to adaptor or client proteins of $\mathrm{p} 97$. 


$$
U^{G 76 V} \text {-GFP }
$$

cell-based degradation assay

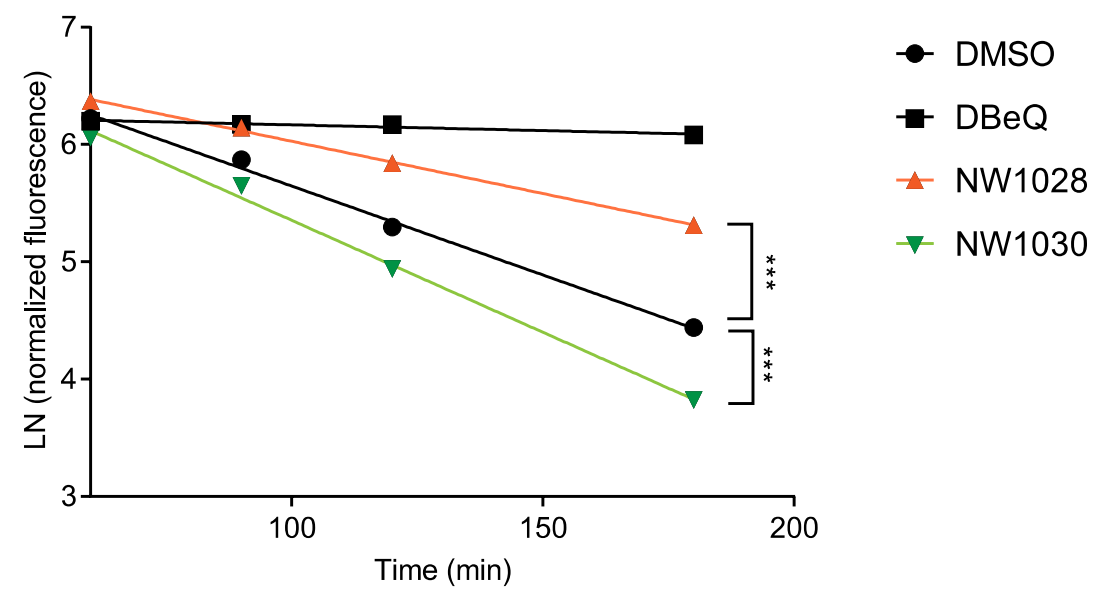

Supplementary Figure S3: Kinetics of UbG76V-GFP degradation for NW1028 and NW1030. Rate constant of degradation $k_{\text {deg }}$ was determined by measuring the slope of the plotted graphs. DBeQ was employed as a positive control.
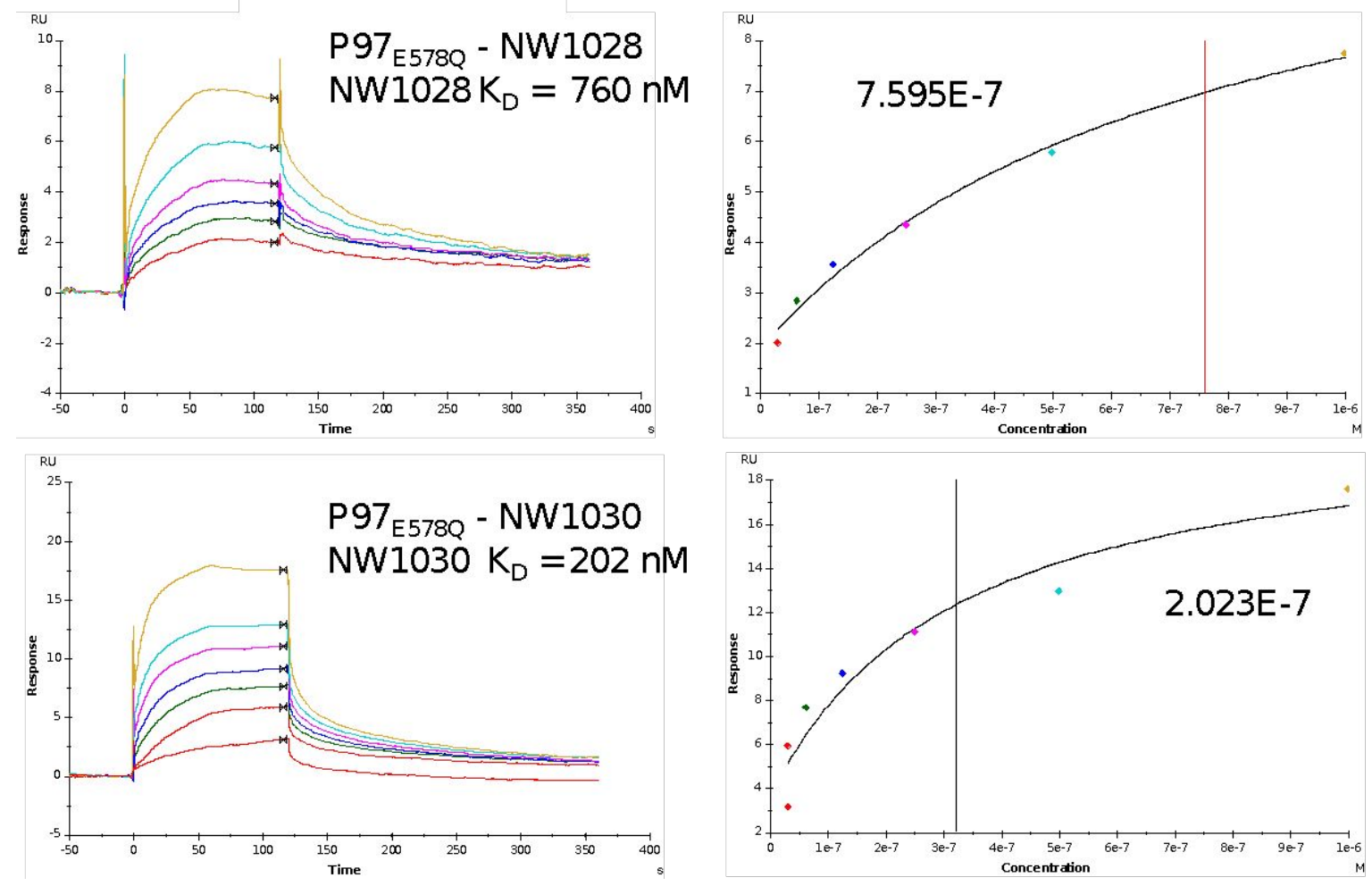

Supplementary Figure S4: SPR affinity measurement of NW1028 and NW1030 on p97(E578Q) a D2 domain Walker B mutant. Affinities determined are unchanged as compared to the $K_{D}$ measured with the WT protein of the ND1L fragment 


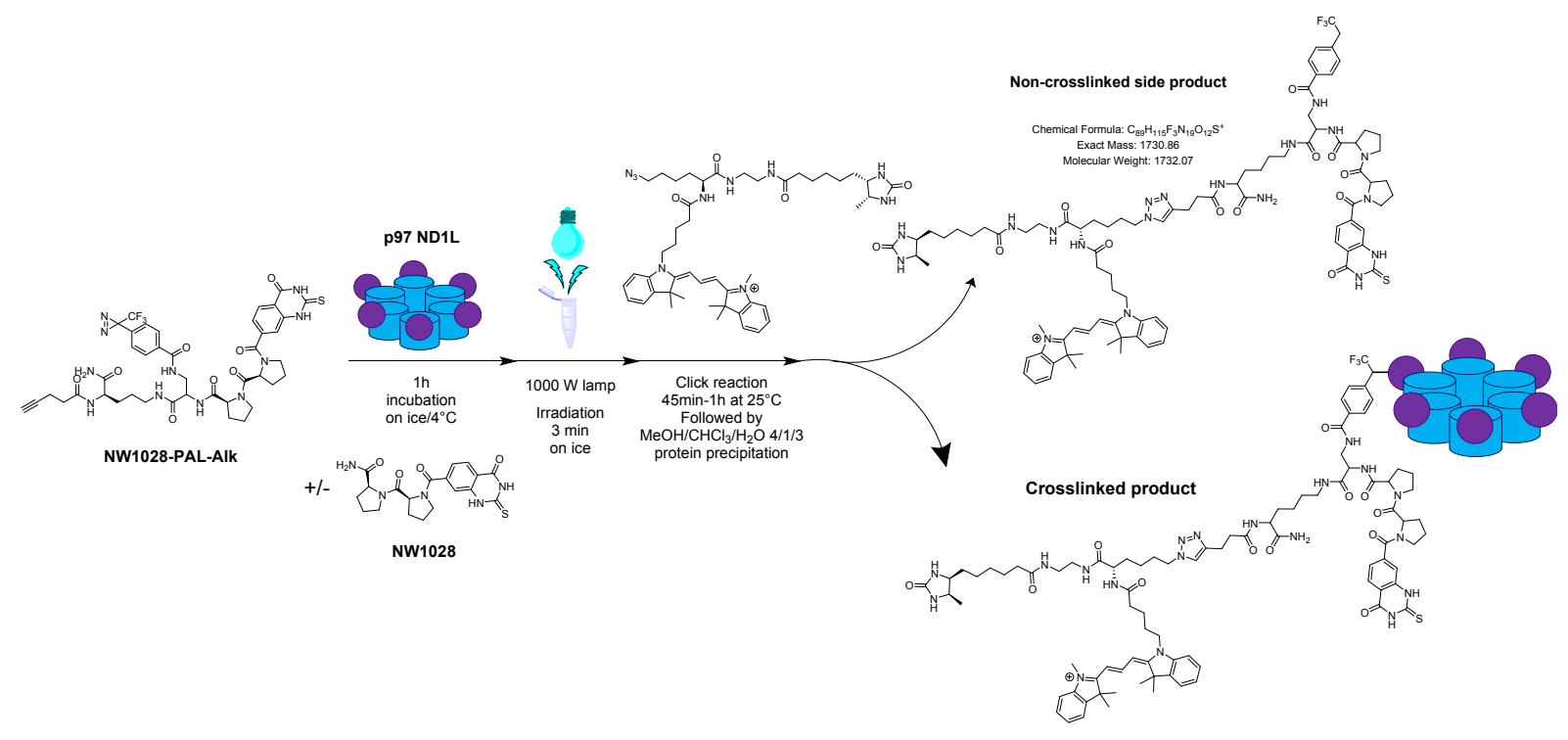

Supplementary Figure S5: Schematic summary of photocrosslinking experiment. Detailed photocrosslinking procedures can be found on the main Methods section of the manuscript. After irradiation, the photocrosslinker will generate a carbene, which in the case of a successful reaction will react with any atom of the protein and yield a covalent adduct. 


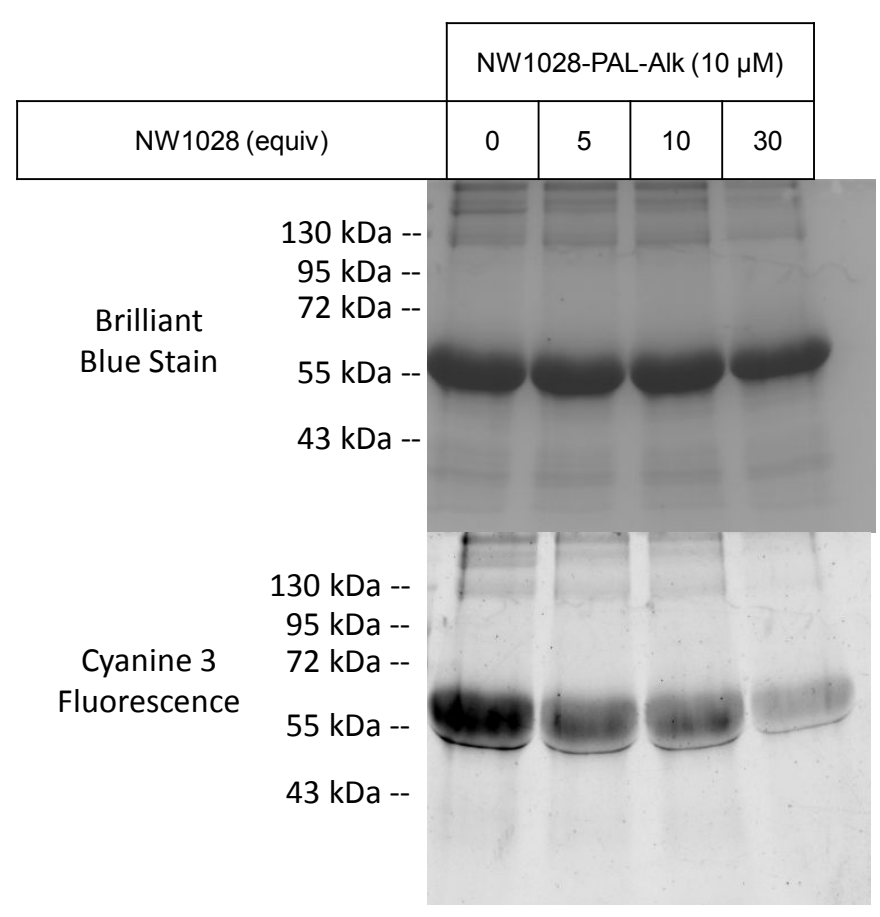

Supplementary Figure S6: NW1028 competes the photo-labelling of p97 ND1L.

Competition experiment of photo-crosslinking of $10 \mu \mathrm{M}$ of NW1028-PAL-Alk with increasing concentrations of NW1028. 


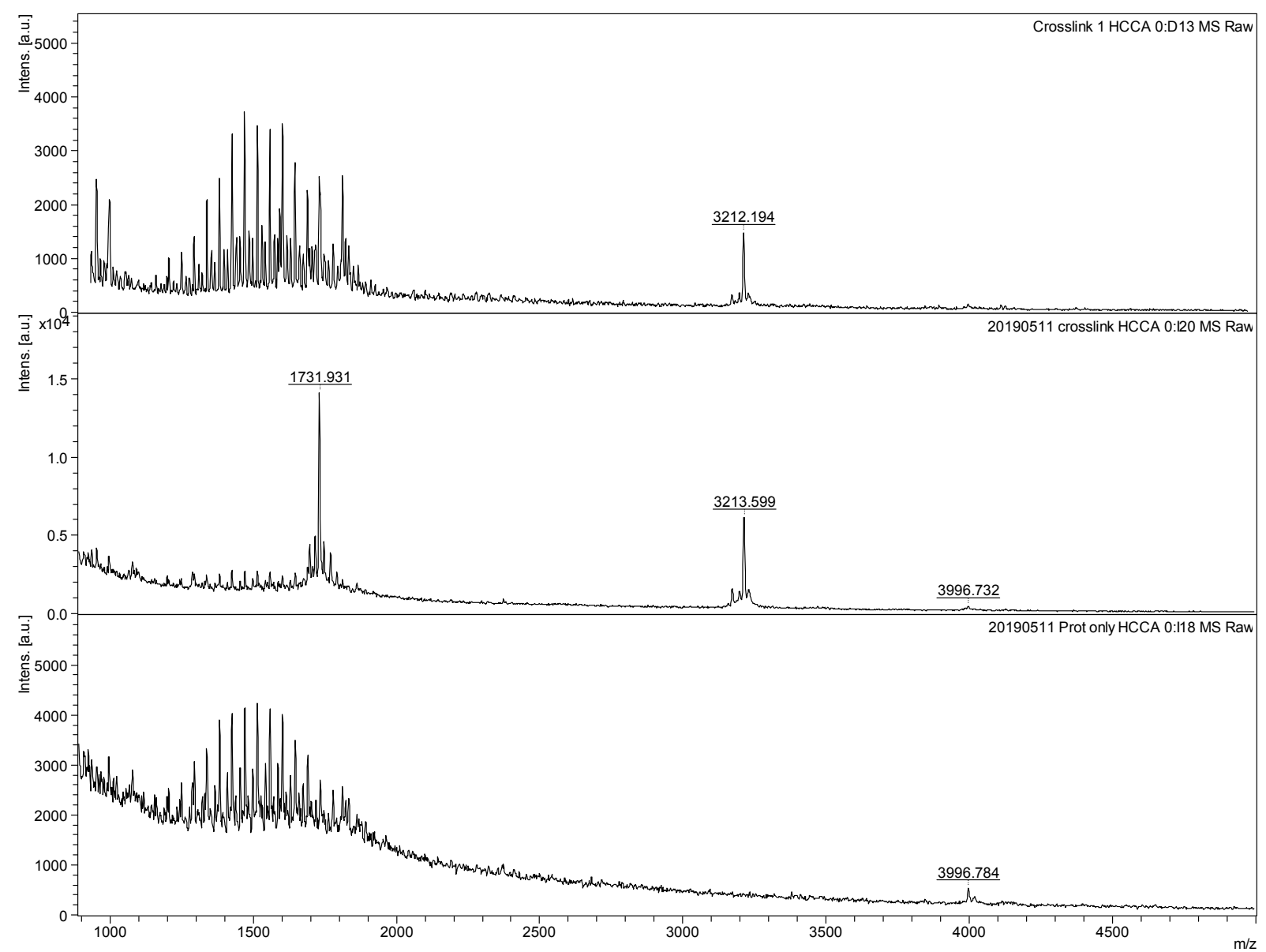

Supplementary Figure S7: MALDIs of photocrosslinking and tryptic digest pulldown of p97 ND1L. Top and middle: MALDI analysis of crosslinking experiment after click reaction, precipitation and SA pulldown. Bottom: MALDI analysis of ND1L fragment irradiated and treated as the samples above, used as negative control. See Supplementary Table 1 for expected tryptic digest MW before and after modification. The massif of peaks from 1100-1600 corresponds to Tween 20 used during the sample wash.

The peak at $1731 \mathrm{~m} / \mathrm{z}$ correspond to the photocrosslinker after irradiation and click reaction, with loss of nitrogen from the diazirine moiety. Indeed the compound has an expected MW of 1732.07 a.m.u., found MW of 1731.931 a.m.u.

The peak at $3212.194 / 3213.539 \mathrm{~m} / \mathrm{z}$ corresponds to a tryptic digest peptide after modification with the photocrosslinker and click reaction. Indeed, the peptide LGDVISIQPCPDVK has an expected MW after modification of 3212.59 a.m.u., MW found by MALDI is 3212.194/3213.539 a.m.u.

The last peak present in the middle and bottom spectra corresponds to some unspecific binding of a tryptic digest peptide to the streptavidin beads. This peptide is present in both the control protein and in the middle sample. It could correspond to the peptide IHVLPIDDTVEGITGNLFEVYLKPYFLEAYRPIR with an expected MW of 3992.63 a.m.u. 

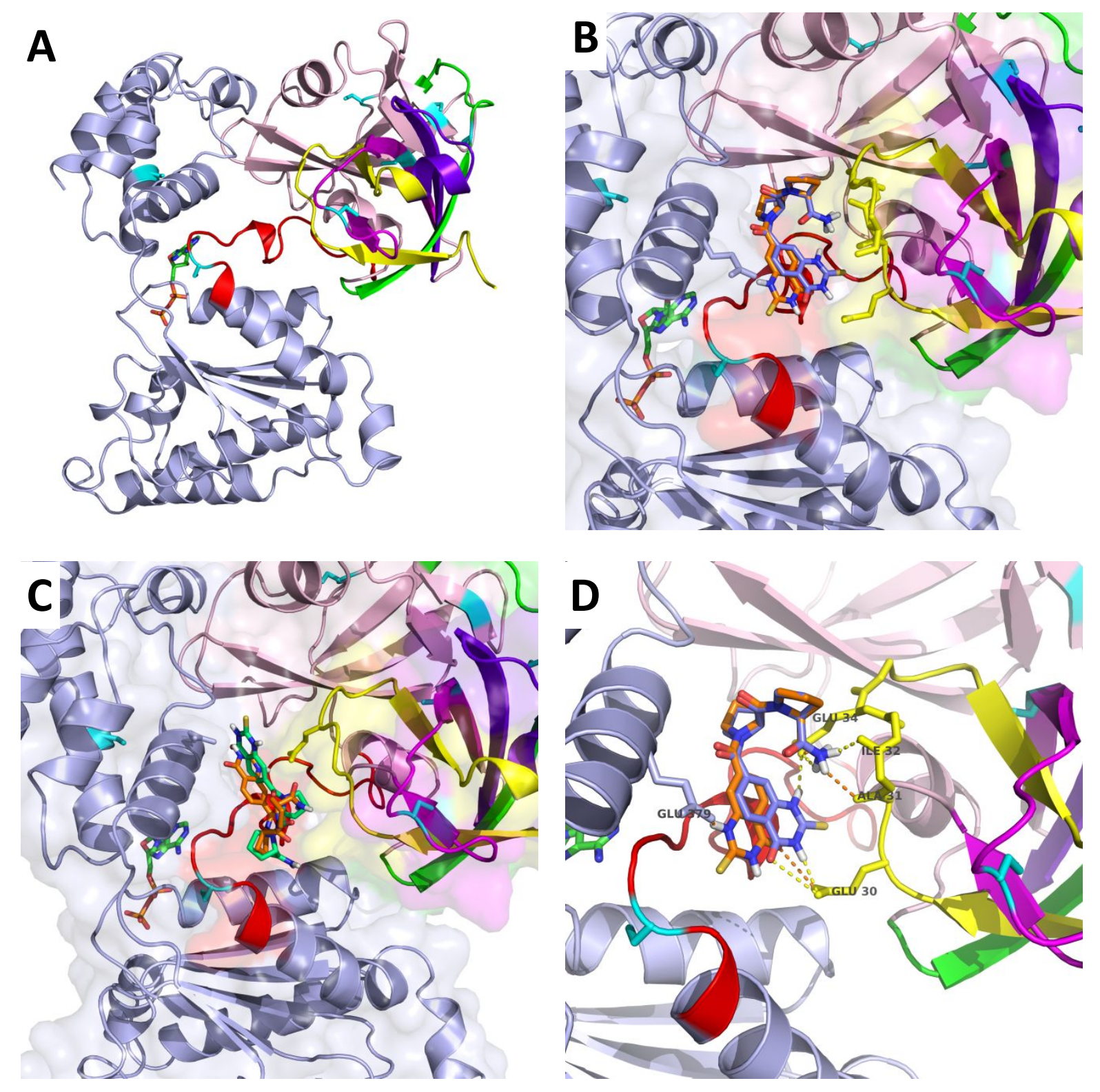

Supplementary Figure S8: High resolution images from the docking of NW1028 on ND1L monomer using autodock vina. (A) Crystal structure of ND1L monomer extracted from PDB: $5 \mathrm{DY}{ }^{1}$, Cysteines are displayed in blue (B) Docking conformations with thiaquinazolinone moiety poiting towards the upper part of the D1-N-domain cleft. (C) Docking conformations with thiaquinazolinone pointing towards the bottom part of the D1-N domain cleft. (D) Top docking conformation as scored by autodock vina. The hydrogen bonds between the ligand and the protein are displayed in yellow.

\footnotetext{
${ }^{1}$ Tang, W. K., and Xia, D. (2016) Role of the D1-D2 Linker of Human VCP/p97 in the Asymmetry and ATPase Activity of the D1-domain, Sci Rep 6, 20037.
} 


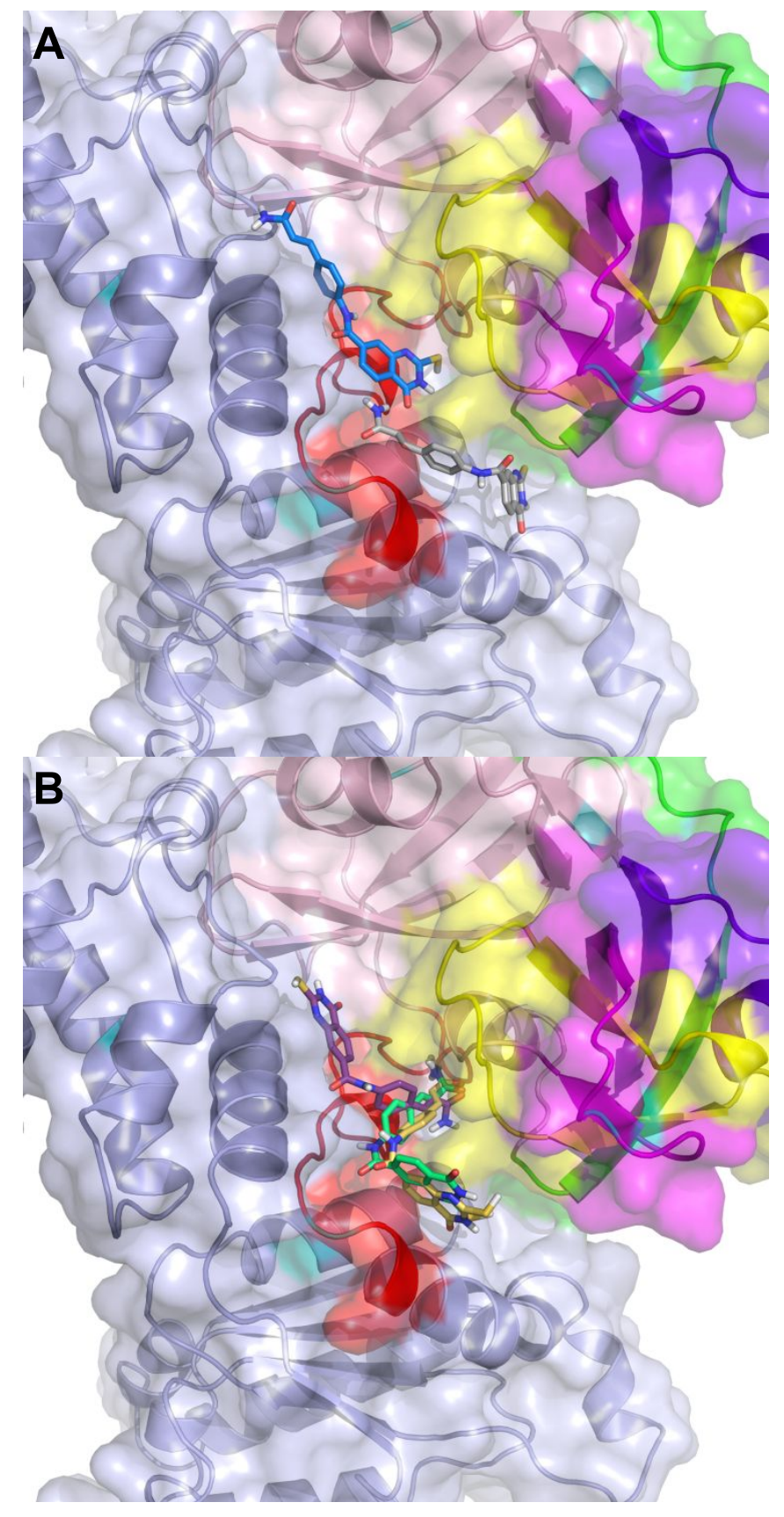

Supplementary Figure S9: Docking of NW1030 on ND1L monomer using autodock vina. Using the same parameters described in the methods section and for the docking of NW1028, NW1030 was docked on ND1L monomer. Two main docking poses emerge, (A) NW1030 positions itself on the clef or (B) the cinnamyl moiety of NW1030 is buried deep into a cavity with the thiaquinazolinone pointing towards different directions in the cleft between the D1 and $\mathrm{N}$ domains. 
A. HeLa MTT Assay

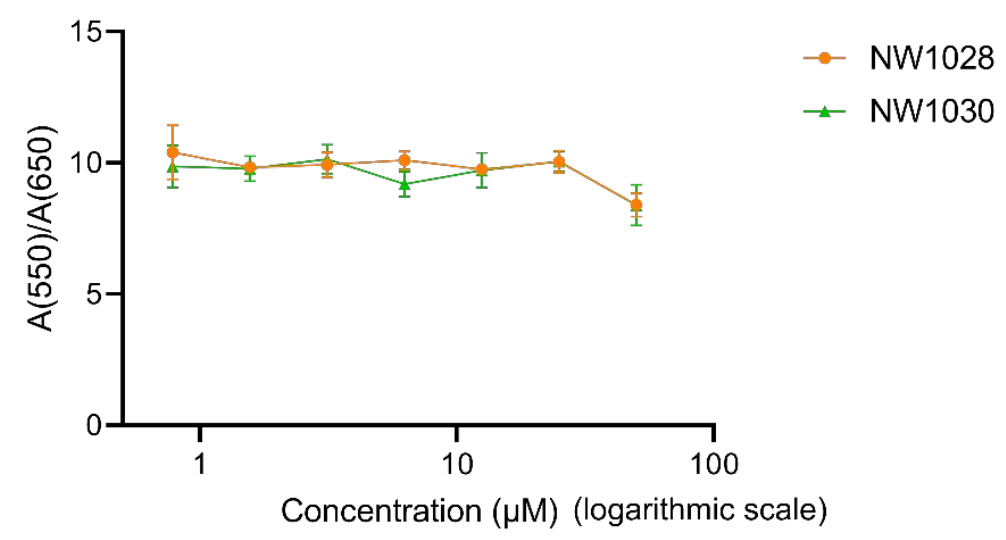

B.

HeLa MTT Assay

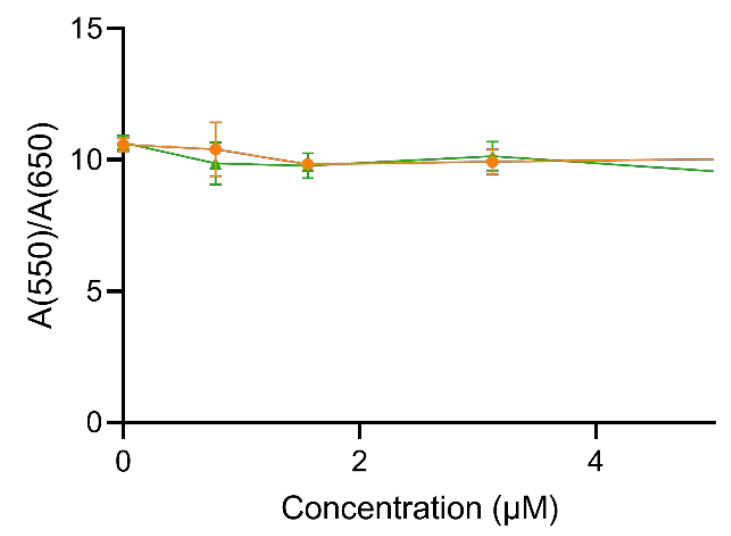

$\rightarrow$ NW1028

$₫$ NW1030

Supplementary Figure S10: MTT assay of NW1028 and NW1030 on HeLa cells. (A) MTT assay on HeLa cells measuring toxicity of compounds using concentrations ranging from 0.7 $\mathrm{uM}$ to $50 \mathrm{uM}$. Minor toxicity was detected at $50 \mathrm{uM}$, which is 5 times the concentration used in the assays. X-axis displayed as log scale. (B) Detail of the graph above limiting concentration from 0 to $5 \mathrm{uM}$. X-axis displayed as linear scale. 


\section{DMSOquine}
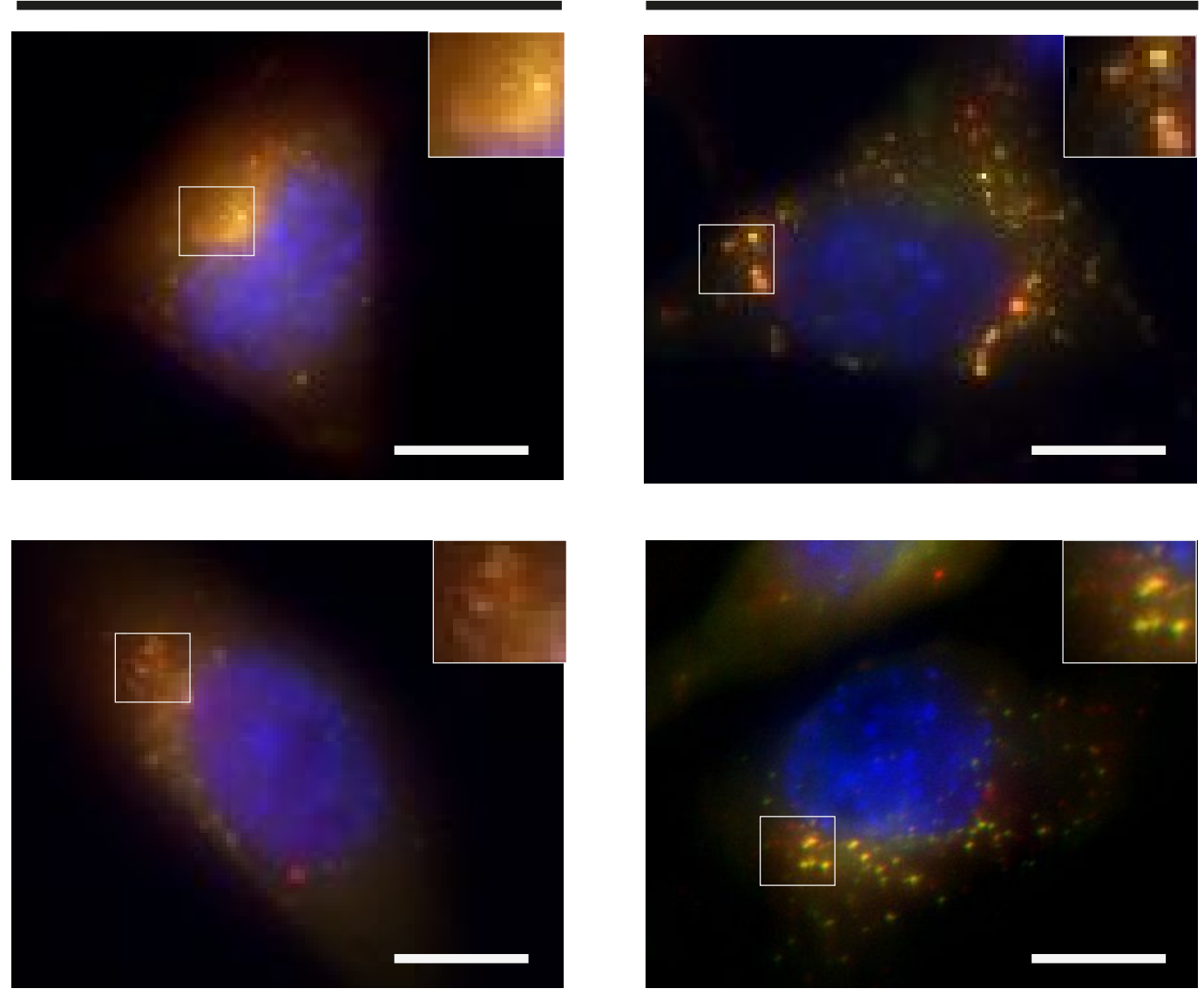

NW1038

Supplementary Figure S11:Enlarged high resolution image of Figure 5B. Representative example of fixed MEF cells (maximum intensity projections) expressing mCherry-GFP-LC3b after 3h treatment with $10 \mu \mathrm{M}$ NW1028, $10 \mu \mathrm{M}$ NW1030, 0.1\% DMSO (negative control) or 10 $\mu \mathrm{M}$ chloroquine (positive control). 
A

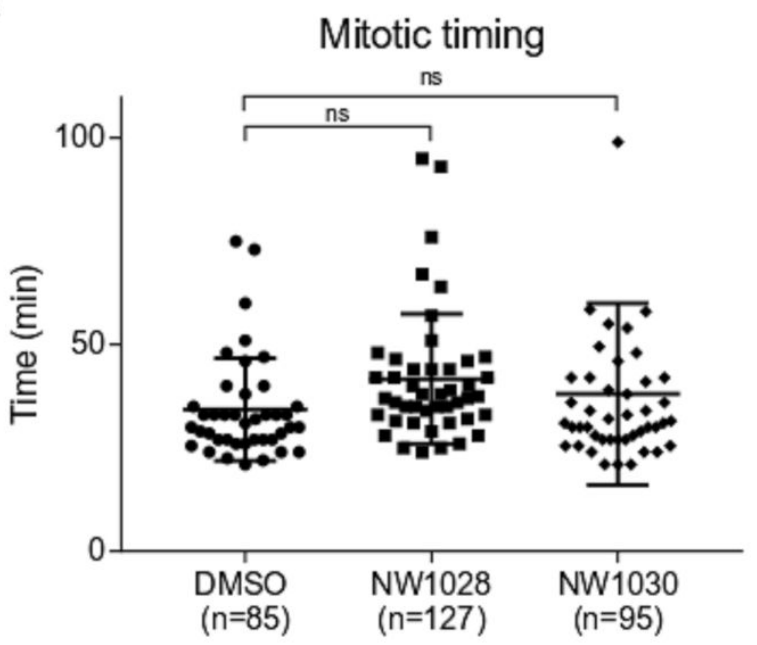

B
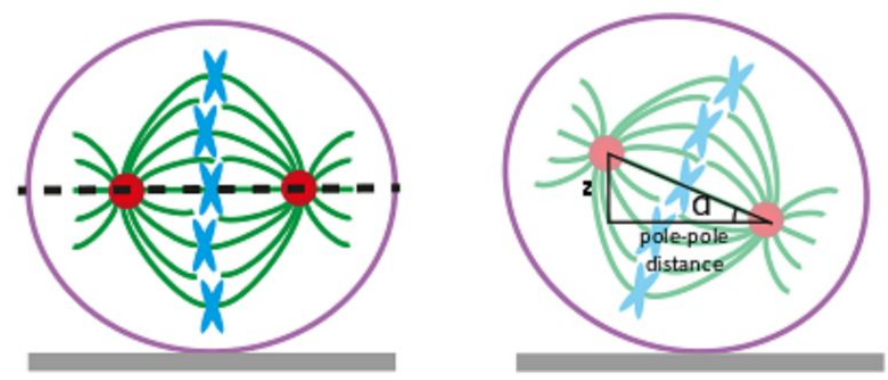

$$
a=\tan \left(\frac{z}{p-p}\right) * \frac{180}{\pi}
$$

Supplementary Figure S12: NW1028 and NW1030 do not affect mitotic timing. (A) Mitotic timing calculated from nuclear envelope breakdown to anaphase onset; one-way ANOVA test show $p>0.05$ for both drugs. Data represent the mean of mitotic timing collected in three independent experiments. Error bars indicate SD. (B) Method to quantify spindle angle in immunostained fixed cells. 


\section{Supplementary Tables and Schemes}

Supplementary Table S1: Expected MW after tryptic digest and modification with photocrosslinker before and after click reaction.

ND1L sequence (identified sequences are highlighted in the color used in Supplementary Figure S5):

MASGADSKGDDLSTAILKQKNRPNRLIVDEAINEDNSVVSLSQPKMDELQLFRGDTVLLKGK KRREAVCIVLSDDTCSDEKIRMNRVVRNNLRVRLGDVISIQPCPDVKYGKRIHVLPIDDTVE GITGNLFEVYLKPYFLEAYRPIRKGDIFLVRGGMRAVEFKVVETDPSPYCIVAPDTVIHCEGE PIKREDEEESLNEVGYDDIGGCRKQLAQIKEMVELPLRHPALFKAIGVKPPRGILLYGPPGTG KLIARAVANETGAFFFLINGPEIMSKLAGESESNLRKAFEEAEKNAPAIIFIDELDAIAPKREKT HGEVERRIVSQLLTLMDGLKQRAHVIVMAATNRPNSIDPALRRFGRFDREVDIGIPDATGRLE ILQIHTKNMKLADDVDLEQVANETHGHVGADLAALCSEAALQAIRKKMDLIDLEDETIDAEVM NSLAVTMDDFRWALSQSNPSALRETVVEVPQVTWEDIG

\begin{tabular}{|r|l|r|r|}
\hline MW & Peptide & $\begin{array}{r}\text { MW + } \\
\text { crosslink }\end{array}$ & $\begin{array}{c}\text { MW + } \\
\text { crosslink } \\
\text { + click }\end{array}$ \\
\hline 146.19 & K & 1039.5 & 1875.04 \\
\hline 146.19 & K & 1039.5 & 1875.04 \\
\hline 146.19 & K & 1039.5 & 1875.04 \\
\hline 146.19 & K & 1039.5 & 1875.04 \\
\hline 146.19 & K & 1039.5 & 1875.04 \\
\hline 146.19 & K & 1039.5 & 1875.04 \\
\hline 174.2 & R & 1067.51 & 1903.05 \\
\hline 174.2 & R & 1067.51 & 1903.05 \\
\hline 174.2 & R & 1067.51 & 1903.05 \\
\hline 174.2 & R & 1067.51 & 1903.05 \\
\hline 174.2 & R & 1067.51 & 1903.05 \\
\hline 174.2 & R & 1067.51 & 1903.05 \\
\hline 174.2 & R & 1067.51 & 1903.05 \\
\hline 203.24 & GK & 1096.55 & 1932.09 \\
\hline 273.34 & VR & 1166.65 & 2002.19 \\
\hline 274.32 & QK & 1167.63 & 2003.17 \\
\hline 275.3 & EK & 1168.61 & 2004.15 \\
\hline 287.36 & IR & 1180.67 & 2016.21 \\
\hline 302.33 & QR & 1195.64 & 2031.18 \\
\hline 366.42 & YGK & 1259.73 & 2095.27 \\
\hline 372.47 & VVR & 1265.78 & 2101.32 \\
\hline 378.43 & FGR & 1271.74 & 2107.28 \\
\hline 391.49 & NMK & 1284.8 & 2120.34 \\
\hline 419.5 & GGMR & 1312.81 & 2148.35 \\
\hline 419.5 & MNR & 1312.81 & 2148.35 \\
\hline 436.47 & FDR & 1329.78 & 2165.32 \\
\hline 471.6 & LIAR & 1364.91 & 2200.45 \\
\hline 515.57 & NNLR & 1408.88 & 2244.42 \\
\hline 592.69 & AVEFK & 1486 & 2321.54 \\
\hline 655.71 & NRPNR & 1549.02 & 2384.56 \\
\hline 699.85 & QLAQIK & 1593.16 & 2428.7 \\
\hline & & & \\
\hline
\end{tabular}




\begin{tabular}{|r|l|r|r|}
\hline 711.86 & HPALFK & 1605.17 & 2440.71 \\
\hline 744.89 & GDTVLLK & 1638.2 & 2473.74 \\
\hline 765.84 & MASGADSK & 1659.15 & 2494.69 \\
\hline 818.97 & GDIFLVR & 1712.28 & 2547.82 \\
\hline 822.87 & AFEEAEK & 1716.18 & 2551.72 \\
\hline 826.86 & THGEVER & 1720.17 & 2555.71 \\
\hline 837.03 & AlGVKPPR & 1730.34 & 2565.88 \\
\hline 986.19 & EMVELPLR & 1879.5 & 2715.04 \\
\hline 1032.16 & GDDLSTAILK & 1925.47 & 2761.01 \\
\hline 1051.23 & MDELQLFR & 1944.54 & 2780.08 \\
\hline 1075.14 & LAGESESNLR & 1968.45 & 2803.99 \\
\hline 1094.32 & LEILQIHTK & 1987.63 & 2823.17 \\
\hline 1172.39 & GILLYGPPGTGK & 2065.7 & 2901.24 \\
\hline 1242.35 & EVDIGIPDATGR & 2135.66 & 2971.2 \\
\hline 1329.48 & WALSQSNPSALR & 2222.79 & 3058.33 \\
\hline 1430.77 & IVSQLLTLMDGLK & 2324.08 & 3159.62 \\
\hline 1483.74 & LGDVISIQPCPDVK & 2377.05 & 3212.59 \\
\hline 1700.86 & ETVVEVPQVTWEDIG & 2594.17 & 3429.71 \\
\hline 1726.89 & EAVCIVLSDDTCSDEK & 2620.2 & 3455.74 \\
\hline 1811.11 & NAPAIIFIDELDAIAPK & 2704.42 & 3539.96 \\
\hline 2129.15 & EDEEESLNEVGYDDIGGCR & 3022.46 & 3858 \\
\hline 2146.5 & AHVIVMAATNRPNSIDPALR & 3039.81 & 3875.35 \\
\hline 2170.4 & LIVDEAINEDNSVVSLSQPK & 3063.71 & 3899.25 \\
\hline 2256.6 & AVANETGAFFFLINGPEIMSK & 3149.91 & 3985.45 \\
\hline 2812.2 & VVETDPSPYCIVAPDTVIHCEGEPIK & 3705.51 & 4541.05 \\
\hline 3102.45 & MDLIDLEDETIDAEVMNSLAVTMDDFR & 3995.76 & 4831.3 \\
\hline & LADDVDLEQVANETHGHVGADLAALCSEAALQA & & \\
3616.96 & IR & 4510.27 & 5345.81 \\
\hline 3992.63 & IHVLPIDDTVEGITGNLFEVYLKPYFLEAYRPIR & 4885.94 & 5721.48 \\
\hline & & & \\
\hline
\end{tabular}


Supplementary Table S2: Peptides identified after tryptic digest incubation with free inhibitor NW1028. DMSO = control experiment; comp = competition with $100 \mu \mathrm{M}$ NW1028. Table is displayed as a heatmap with values as follow: red $<10^{6} ; 10^{6}<$ yellow $<10^{8}$; green $>10^{8}$. The selected peptide sequences in yellow present a difference in cysteine modification after treatment with iodoacetamide. In most cases, the cysteines appeared not to be modified in presence of the inhibitor. In the case of the sequences LGDVISIQPCPDVK and EDEEESLNEVGYDDIGGCR, both peptides appear with Cys modification but a 100-fold difference is present between DMSO samples and the competition experiments. In this case, the peptide are detected as being non-modified in the competition samples, which is not the case in the DMSO sample.

\begin{tabular}{|c|c|c|c|c|c|c|c|c|c|c|c|c|}
\hline Annotated Sequence & Modifications & Positions & $\begin{array}{c}\text { \# Missed } \\
\text { Cleavages }\end{array}$ & Theo. $\mathrm{MH}+[\mathrm{Da}]$ & DMSO1 & DMSO2 & DMSO3 & DMSO4 & Comp1 & Comp2 & Comp3 & Comp4 \\
\hline$[\mathrm{K}]$. LAGESESNLRK.[A] & & [278-288] & 1 & 1203.632791 & $3 E+08$ & $3 E+08$ & $3 E+08$ & $4 \mathrm{E}+08$ & $3 E+08$ & $2 E+08$ & $6 E+08$ & $9 E+07$ \\
\hline [R].LIVDEAINEDNSWVLSQPK.[M] & & {$[26-45]$} & 0 & 2170.123768 & $6 E+09$ & $1 E+10$ & $7 E+09$ & $5 E+09$ & $7 E+09$ & $1 E+10$ & $1 E+10$ & $9 \mathrm{E}+09$ \\
\hline [R].INSQLLTLMDGLK.[Q] & & {$[324-336]$} & 0 & 1430.828713 & $4 \mathrm{E}+09$ & $5 E+09$ & $9 E+09$ & $2 E+09$ & $7 E+09$ & $3 E+09$ & $5 E+09$ & $3 E+09$ \\
\hline [R].IVSQLLTLMDGLK.[Q] & 1xOxidation [M9] & [324-336] & 0 & 1446.823628 & $1 E+07$ & $3 E+06$ & $9 E+06$ & $1 E+08$ & $2 E+07$ & $1 E+07$ & $2 E+07$ & $5 E+06$ \\
\hline [R].EVDIGIPDATGRLEILQIHTK.[N] & & [366-386] & 1 & 2318.271436 & $3 E+07$ & $3 E+07$ & $1 E+07$ & $0 E+00$ & $6 E+06$ & $3 E+06$ & $5 E+07$ & $0 E+00$ \\
\hline [K].MDELQLFRGDTVLLK.[G] & & {$[46-60]$} & 1 & 1777.951682 & $5 E+07$ & $6 \mathrm{E}+07$ & $3 E+07$ & $2 E+07$ & $0 E+00$ & $9 E+06$ & $1 E+07$ & $0 E+00$ \\
\hline [R].IVSQLLTLMDGLKQR.[A] & & [324-338] & 1 & 1714.988402 & $2 E+07$ & $1 E+07$ & $7 E+06$ & $4 E+06$ & $2 E+07$ & $1 E+07$ & $4 \mathrm{E}+07$ & $5 E+06$ \\
\hline$[\mathrm{K}]$.NAPAIIFIDELDAIAPK.[R] & & [296-312] & 0 & 1810.994927 & $9 E+09$ & $1 \mathrm{E}+10$ & $1 E+10$ & $8 \mathrm{E}+09$ & $1 E+10$ & $1 \mathrm{E}+10$ & $6 E+09$ & $1 E+10$ \\
\hline [K].NAPAIIFIDELDAIAPKR.[E] & & [296-313] & 1 & 1967.096038 & $8 E+06$ & $2 \mathrm{E}+07$ & $8 \mathrm{E}+06$ & $0 E+00$ & $1 E+07$ & $9 E+06$ & $1 E+07$ & $7 E+06$ \\
\hline$[\mathrm{K}]$.AFEEAEKNAPAIIFIDELDAIAPKR.[E] & & [289-313] & 2 & 2771.461421 & $2 E+06$ & $1 \mathrm{E}+07$ & $3 \mathrm{E}+06$ & $0 \mathrm{E}+00$ & $0 E+00$ & $3 E+06$ & $0 \mathrm{E}+00$ & $0 \mathrm{E}+00$ \\
\hline$[R]$ KAFEEAEKNAPAIIFIDELDAIAPK.[R] & & [288-312] & 2 & 2743.455273 & $5 \mathrm{E}+06$ & $3 \mathrm{E}+07$ & $7 \mathrm{E}+06$ & $0 E+00$ & $0 E+00$ & $4 \mathrm{E}+06$ & $3 \mathrm{E}+06$ & $0 \mathrm{E}+00$ \\
\hline [R].AVANETGAFFFLINGPEIMSK.[L] & & {$[257-277]$} & 0 & 2256.136916 & $2 E+09$ & $3 \mathrm{E}+09$ & $5 \mathrm{E}+09$ & $2 E+09$ & $3 \mathrm{E}+09$ & $4 \mathrm{E}+09$ & $3 \mathrm{E}+08$ & $2 \mathrm{E}+09$ \\
\hline [R].AVANETGAFFFLINGPEIMSK.[L] & 1XOxidation [M19] & [257-277] & 0 & 2272.131831 & $1 \mathrm{E}+08$ & $1 \mathrm{E}+08$ & $3 E+08$ & $2 E+08$ & $2 E+08$ & $3 E+08$ & $4 \mathrm{E}+07$ & $1 \mathrm{E}+08$ \\
\hline [K].AFEEAEKNAPAIIFIDELDAIAPK.[R] & & [289-312] & 1 & 2615.36031 & $1 E+07$ & $4 \mathrm{E}+07$ & $7 E+06$ & $6 \mathrm{E}+06$ & $0 \mathrm{E}+00$ & $2 E+07$ & $2 E+07$ & $6 E+06$ \\
\hline [K].REDEEESLNEVGYDDIGGCRK.[Q] & 1xCarbamidomethyl [C19] & [191-211] & 2 & 2470.078686 & $5 E+07$ & $6 \mathrm{E}+07$ & $7 E+07$ & $2 E+07$ & $0 E+00$ & $0 E+00$ & $0 E+00$ & $0 \mathrm{E}+00$ \\
\hline [R].REAVCIVLSDDTCSDEK.[] & 2xCarbamidomethyl [C5; C13] & {$[65-81]$} & 1 & 1996.895031 & $6 \mathrm{E}+07$ & $6 \mathrm{E}+07$ & $7 E+07$ & $4 E+07$ & $0 E+00$ & $0 \mathrm{E}+00$ & $0 E+00$ & $0 E+00$ \\
\hline [R].LGDVISIQPCPDVKYGKR.[] & 1xCarbamidomethyl [C10] & [96-113] & 2 & 2045.084821 & $0 E+00$ & $3 E+06$ & $0 \mathrm{E}+00$ & $0 \mathrm{E}+00$ & $0 E+00$ & $0 \mathrm{E}+00$ & $0 \mathrm{E}+00$ & $0 \mathrm{E}+00$ \\
\hline [K].REDEEESLNEVGYDDIGGCR.[K] & 1xCarbamidomethyl [C19] & [191-210] & 1 & 2341.983723 & $2 E+08$ & $2 E+08$ & $2 E+08$ & $1 E+08$ & $8 E+06$ & $0 \mathrm{E}+00$ & $8 E+06$ & $0 \mathrm{E}+00$ \\
\hline [R].EAVCILSDDTCSDEKIR.[M] & $2 \times$ Carbamidomethyl [C4; C12] & [66-83] & 1 & 2109.979095 & $2 E+08$ & $6 \mathrm{E}+07$ & $2 E+08$ & $9 \mathrm{E}+07$ & $0 \mathrm{E}+00$ & $0 \mathrm{E}+00$ & $0 \mathrm{E}+00$ & $0 \mathrm{E}+00$ \\
\hline [R].EAVCILSDDTCSDEK.[] & 2xCarbamidomethyl [C4; C12] & {$[66-81]$} & 0 & 1840.79392 & $3 E+09$ & $2 E+09$ & $3 E+09$ & $2 E+09$ & $0 \mathrm{E}+00$ & $0 \mathrm{E}+00$ & $0 \mathrm{E}+00$ & $0 \mathrm{E}+00$ \\
\hline [R].VRLGDVISIQPCPDVK.[Y] & 1xCarbamidomethyl [C12] & [94-109] & 1 & 1795.97348 & $4 \mathrm{E}+07$ & $2 \mathrm{E}+07$ & $5 \mathrm{E}+07$ & $2 \mathrm{E}+07$ & $0 \mathrm{E}+00$ & $0 \mathrm{E}+00$ & $0 \mathrm{E}+00$ & $0 \mathrm{E}+00$ \\
\hline$[\mathrm{K}] . N R P N R L I V D E A I N E D N S W S L S Q P K .[M]$ & & {$[21-45]$} & 1 & 2807.464609 & $7 E+06$ & $4 \mathrm{E}+07$ & $3 \mathrm{E}+07$ & $1 E+07$ & $0 \mathrm{EE}+00$ & $0 \mathrm{E}+00$ & $0 \mathrm{E}+00$ & $0 \mathrm{E}+00$ \\
\hline$[\mathrm{K}] . M D E L Q L F R G D T V L L K G K .[\mathrm{K}]$ & & [46-62] & 2 & 1963.068108 & $2 \mathrm{E}+06$ & $5 \mathrm{E}+06$ & $0 \mathrm{E}+00$ & $0 \mathrm{E}+00$ & $0 \mathrm{E}+00$ & $0 \mathrm{E}+00$ & $0 \mathrm{E}+00$ & $0 E+00$ \\
\hline [R].RIVSQLLTLMDGLKQR.[A] & & [323-338] & 2 & 1871.089513 & $4 \mathrm{E}+06$ & $4 \mathrm{E}+06$ & $0 \mathrm{E}+00$ & $0 \mathrm{E}+00$ & $0 \mathrm{E}+00$ & $0 \mathrm{E}+00$ & $9 \mathrm{E}+06$ & $0 \mathrm{E}+00$ \\
\hline [R].RIVSQLLTLMDGLK.[Q] & 1XOxidation [M10] & [323-336] & 1 & 1602.924739 & $3 E+06$ & $6 E+06$ & $5 E+06$ & $2 E+07$ & $6 E+06$ & $6 E+06$ & $1 E+07$ & $0 E+00$ \\
\hline [K].REKTHGEVER.[R] & & {$[313-322]$} & 2 & 1240.639273 & $2 E+05$ & $0 E+00$ & $0 E+00$ & $0 E+00$ & $\mathrm{OE}+00$ & $0 E+00$ & $0 E+00$ & $4 \mathrm{E}+05$ \\
\hline [R].RIVSQLLTLMDGLK.[Q] & & [323-336] & 1 & 1586.929824 & $2 E+08$ & $1 \mathrm{E}+08$ & $4 \mathrm{E}+08$ & $7 \mathrm{E}+07$ & $1 \mathrm{E}+08$ & $1 E+08$ & $2 E+08$ & $1 \mathrm{E}+08$ \\
\hline [K].QLAQIKEMVELPLR.[H] & & [212-225] & 1 & 1667.951288 & $0 \mathrm{E}+00$ & $0 \mathrm{E}+00$ & $0 \mathrm{E}+00$ & $0 \mathrm{E}+00$ & $1 E+07$ & $4 E+06$ & $8 E+06$ & $1 \mathrm{E}+07$ \\
\hline$[\mathrm{K}]$. LAGESESNLR.[K] & & [278-287] & 0 & 1075.537828 & $1 E+10$ & $1 E+10$ & $1 E+10$ & $7 \mathrm{E}+09$ & $1 \mathrm{E}+10$ & $1 \mathrm{E}+10$ & $1 E+10$ & $9 \mathrm{E}+09$ \\
\hline [R].AHVIMMAATNRPNSIDPALRR.[F] & & [339-359] & 1 & 2302.256077 & $6 \mathrm{E}+08$ & $7 \mathrm{E}+08$ & $8 E+08$ & $2 E+08$ & $3 E+08$ & $8 \mathrm{E}+08$ & $7 E+08$ & $2 \mathrm{E}+08$ \\
\hline [R].AHVMMAATNRPNSIDPALRR.[F] & 1xOxidation [M6] & [339-359] & 1 & 2318.250992 & $1 E+07$ & $6 \mathrm{E}+06$ & $1 E+07$ & $2 E+07$ & $9 \mathrm{EE}+06$ & $2 E+07$ & $1 E+07$ & $1 E+07$ \\
\hline [R].AHVIVMAATNRPNSIDPALR.[R] & & [339-358] & 0 & 2146.154966 & $2 \mathrm{E}+09$ & $8 \mathrm{E}+08$ & $2 E+09$ & $4 \mathrm{E}+08$ & $1 E+09$ & $4 \mathrm{E}+08$ & $2 E+09$ & $4 E+08$ \\
\hline [R].AHVIVMAATNRPNSIDPALR.[R] & 1xOxidation [MG] & [339-358] & 0 & 2162.149881 & $1 E+08$ & $1 E+08$ & $1 E+08$ & $2 E+08$ & $1 E+08$ & $2 E+08$ & $2 E+08$ & $5 E+07$ \\
\hline [R].LEILQIHTK.[N] & & [378-386] & 0 & 1094.656821 & $2 E+09$ & $2 E+09$ & $3 E+09$ & $2 E+09$ & $2 E+09$ & $3 E+09$ & $3 E+09$ & $2 \mathrm{E}+09$ \\
\hline [R].EDEEESLNEVGYDDIGGCRK.[Q] & 1xCarbamidomethyl [C18] & [192-211] & 1 & 2313.977575 & $1 E+09$ & $9 E+08$ & $1 E+09$ & $4 E+08$ & $0 E+00$ & $0 E+00$ & $0 E+00$ & $0 E+00$ \\
\hline [K].EMVELPLR.[H] & 1xOxidation [M2] & [218-225] & 0 & 1002.528843 & $2 E+08$ & $1 E+08$ & $2 E+08$ & $5 E+08$ & $4 \mathrm{E}+08$ & $3 E+08$ & $4 \mathrm{E}+08$ & $2 E+08$ \\
\hline [R].WALSQSNPSALR.[E] & & [454-465] & 0 & 1329.690974 & $2 E+10$ & $2 E+10$ & $2 E+10$ & $1 \mathrm{E}+10$ & $1 \mathrm{E}+10$ & $2 E+10$ & $1 E+10$ & $7 \mathrm{E}+09$ \\
\hline$[\mathrm{K}]$. GDDLSTAILK.[Q] & & [9-18] & 0 & 1032.557166 & $8 \mathrm{E}+09$ & $9 E+09$ & $1 E+10$ & $6 \mathrm{E}+09$ & $8 \mathrm{E}+09$ & $9 \mathrm{E}+09$ & $9 \mathrm{E}+09$ & $6 E+09$ \\
\hline [K].WETDPSPYCIVAPDTVIHCEGEPIK.[R] & 2xCarbamidomethyl [C10; C20] & [165-190] & 0 & 2925.400871 & $4 \mathrm{E}+08$ & $2 E+08$ & $4 \mathrm{E}+08$ & $2 \mathrm{E}+08$ & $2 E+06$ & $4 \mathrm{E}+06$ & $4 \mathrm{E}+06$ & $0 \mathrm{E}+00$ \\
\hline$[\mathrm{K}]$. EMVELPLRHPALFK.[A] & & [218-231] & 1 & 1679.930159 & $2 E+07$ & $2 E+07$ & $2 \mathrm{E}+07$ & $8 E+06$ & $1 E+07$ & $2 E+07$ & $6 \mathrm{E}+07$ & $5 \mathrm{E}+06$ \\
\hline [R].EVDIGIPDATGR.[L] & & [366-377] & 0 & 1242.632456 & $2 E+10$ & $2 \mathrm{E}+10$ & $2 E+10$ & $1 \mathrm{E}+10$ & $1 E+10$ & $2 \mathrm{E}+10$ & $2 E+10$ & $1 \mathrm{E}+10$ \\
\hline [R].FDREVDIGIPDATGR.[L] & & {$[363-377]$} & 1 & 1660.828924 & $4 \mathrm{E}+08$ & $2 \mathrm{E}+08$ & $3 \mathrm{E}+08$ & $2 E+08$ & $2 E+08$ & $2 \mathrm{E}+08$ & $3 \mathrm{E}+08$ & $1 \mathrm{E}+08$ \\
\hline [RK].GILLYGPPGTGK.[T] & & [240-251] & 0 & 1172.667385 & $2 E+10$ & $2 E+10$ & $2 E+10$ & $1 E+10$ & $1 E+10$ & $2 E+10$ & $2 \mathrm{E}+10$ & $1 \mathrm{E}+10$ \\
\hline [R].LGDVISIQPCPDVK.[Y] & & [96-109] & 0 & 1483.782491 & $0 E+00$ & $0 E+00$ & $0 E+00$ & $0 E+00$ & $2 E+07$ & $3 E+07$ & $3 E+07$ & $4 E+06$ \\
\hline [R].LGDVISIQPCPDVK.YY] & 1xCarbamidomethyl [C10] & [96-109] & 0 & 1540.803955 & $1 E+10$ & $1 E+10$ & $1 E+10$ & $6 E+09$ & $5 E+08$ & $6 \mathrm{E}+08$ & $6 \mathrm{E}+08$ & $2 E+08$ \\
\hline [K].MDELQLFR.[G] & & {$[46-53]$} & 0 & 1051.524092 & $7 E+09$ & $8 E+09$ & $7 E+09$ & $5 E+09$ & $9 E+09$ & $1 E+10$ & $1 E+10$ & $7 E+09$ \\
\hline$[\mathrm{K}] . M D E L Q L F R .[G]$ & 1xOxidation [M1] & [46-53] & 0 & 1067.519007 & $1 E+08$ & $8 E+07$ & $1 E+08$ & $4 E+08$ & $3 \mathrm{E}+08$ & $2 E+08$ & $3 E+08$ & $2 E+08$ \\
\hline [R].EDEEESLNEVGYDDIGGCR.[K] & & [192-210] & 0 & 2128.861148 & $0 E+00$ & $0 \mathrm{E}+00$ & $0 E+00$ & $0 \mathrm{E}+00$ & $1 \mathrm{E}+07$ & $8 E+06$ & $1 E+07$ & $0 \mathrm{E}+00$ \\
\hline [R].EDEEESLNEVGYDDIGGCR.[K] & 1XCarbamidomethyl [C18] & [192-210] & 0 & 2185.882612 & $2 E+09$ & $3 E+09$ & $2 E+09$ & $1 \mathrm{E}+09$ & $9 \mathrm{EE}+07$ & $2 E+08$ & $9 E+07$ & $7 E+07$ \\
\hline [R].GILLYGPPGTGKTLIAR.[A] & & [240-256] & 1 & 1727.021416 & $0 \mathrm{E}+00$ & $4 \mathrm{E}+06$ & $0 \mathrm{E}+00$ & $0 \mathrm{E}+00$ & $2 \mathrm{E}+07$ & $6 \mathrm{E}+06$ & $2 E+07$ & $9 \mathrm{E}+06$ \\
\hline$[\mathrm{K}]$. EMVELPLRHPALFK.[A] & 1xOxidation [M2] & [218-231] & 1 & 1695.925074 & $0 \mathrm{E}+00$ & $0 \mathrm{E}+00$ & $0 E+00$ & $0 \mathrm{E}+00$ & $0 E+00$ & $3 E+06$ & $0 \mathrm{E}+00$ & $0 \mathrm{E}+00$ \\
\hline$[\mathrm{K}] . E M N E L P L R .[\mathrm{H}]$ & & [218-225] & 0 & 986.5339284 & $1 \mathrm{E}+10$ & $1 E+10$ & $1 \mathrm{E}+10$ & $7 E+09$ & $8 E+09$ & $1 E+10$ & $1 E+10$ & $7 E+09$ \\
\hline [K].NAPAIIFIDELDAIAPKREK.[T] & & [296-315] & 2 & 2224.233594 & $0 \mathrm{EE}+00$ & $0 \mathrm{E}+00$ & $0 E+00$ & $0 \mathrm{E}+00$ & $0 \mathrm{E}+00$ & $0 \mathrm{E}+00$ & $0 \mathrm{E}+00$ & $0 E+00$ \\
\hline
\end{tabular}


Supplementary Table S3: Affinities of the 9 best binding modes determined by autodock vina ${ }^{2}$ using ND1L monomer as a receptor and NW1028 (1) as a ligand. NW1028 (1) 3D structure was generated on Chemdraw 3D and its energy was minimized. P97 ND1L monomer structure was extracted from PDB: $5 \mathrm{DYl}^{3}$ using residues from 26 to 460 . Output gave 9 best conformations, 4 of which were almost similar varying mostly on the position of the quinazoline moiety.

\begin{tabular}{|l|l|l|l|} 
& \multicolumn{2}{|c|}{ Dist from best mode } \\
\hline mode & Affinity $(\mathrm{kcal} / \mathrm{mol})$ & rmsd l.b. & rmsd u.b. \\
\hline 1 & -7.1 & 0.000 & 0.000 \\
\hline 2 & -7.0 & 2.265 & 4.150 \\
\hline 3 & -7.0 & 4.541 & 7.784 \\
\hline 4 & -7.0 & 2.391 & 4.259 \\
\hline 5 & -6.9 & 3.986 & 5.936 \\
\hline 6 & -6.9 & 4.549 & 7.388 \\
\hline 7 & -6.9 & 4.163 & 6.771 \\
\hline 8 & -6.8 & 3.265 & 7.045 \\
\hline 9 & -6.8 & 3.448 & 6.959 \\
\hline
\end{tabular}

2 Trott, O., and Olson, A. J. (2010) AutoDock Vina: improving the speed and accuracy of docking with a new scoring function, efficient optimization, and multithreading, J Comput Chem 31, 455-461.

${ }^{3}$ Tang, W. K., and Xia, D. (2016) Role of the D1-D2 Linker of Human VCP/p97 in the Asymmetry and ATPase Activity of the D1-domain, Sci Rep 6, 20037. 
Supplementary Table S4: Structure and numbers of compounds used in the paper

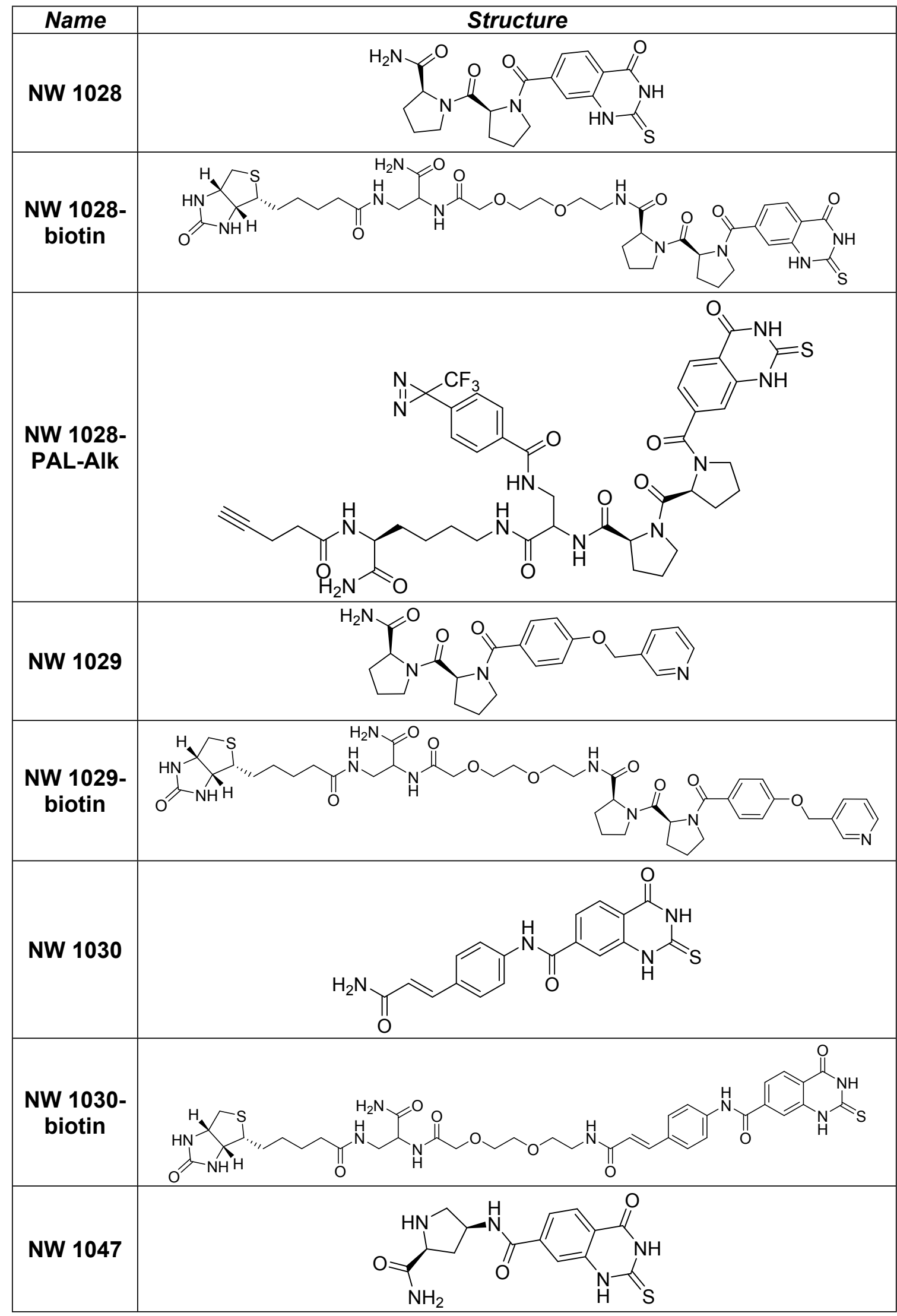




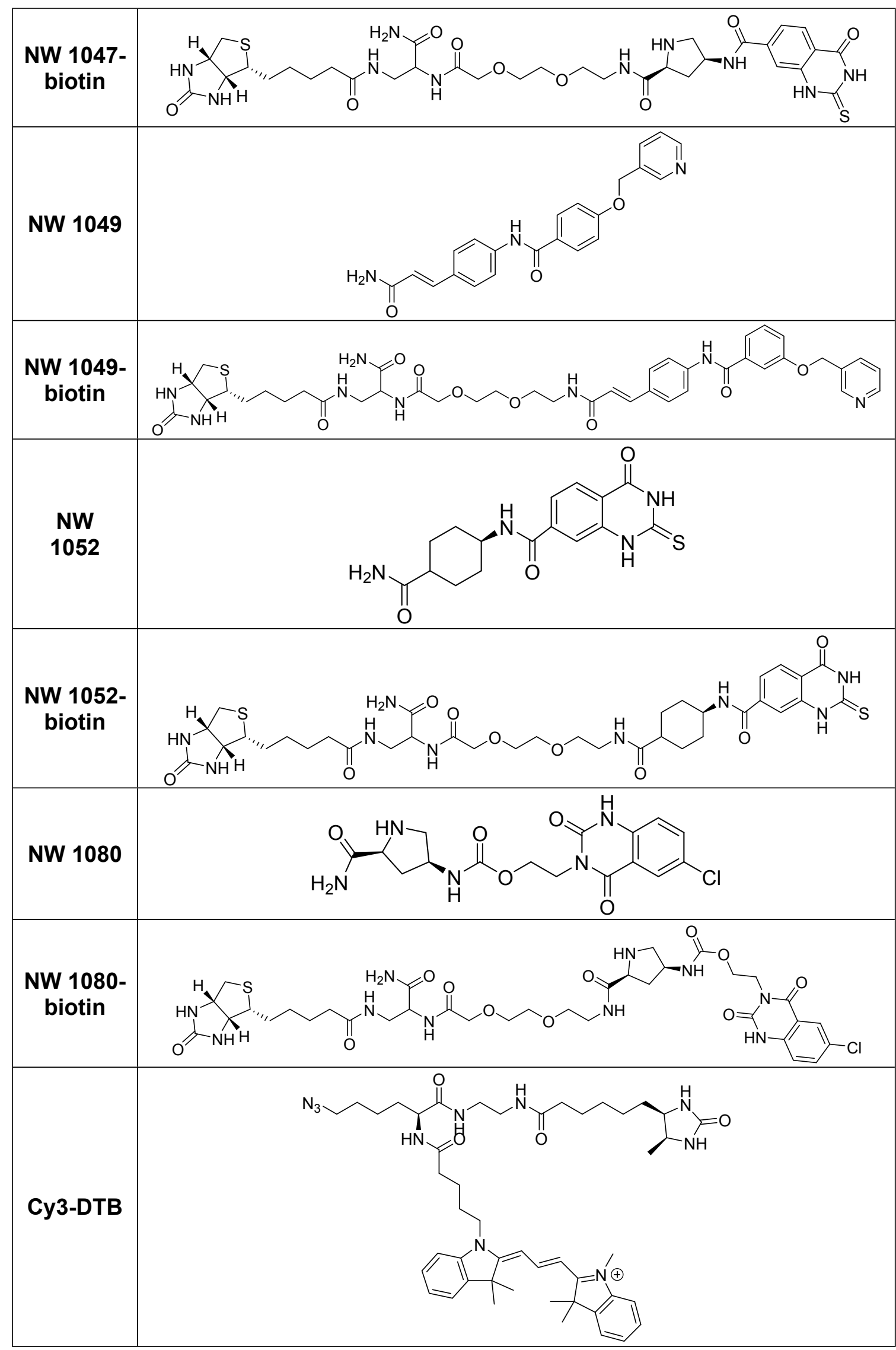




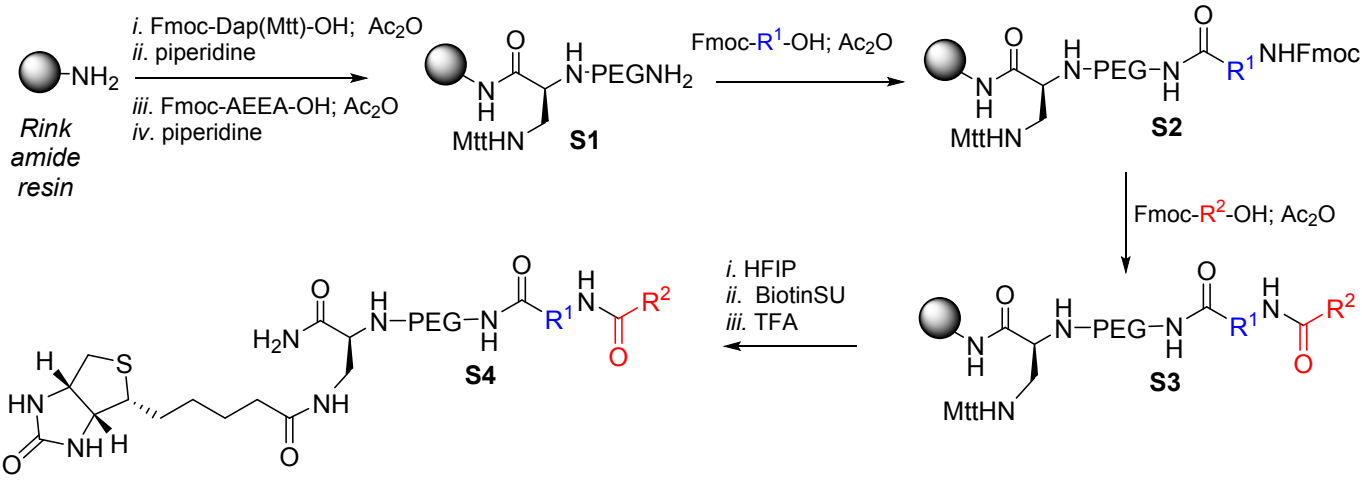

Supplementary Scheme S1: Synthetic scheme of biotinylated compounds.

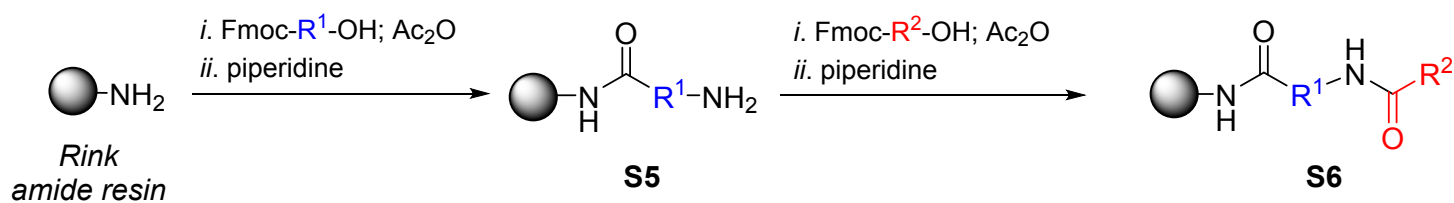

Supplementary Scheme S2: Synthetic scheme of hit compounds.

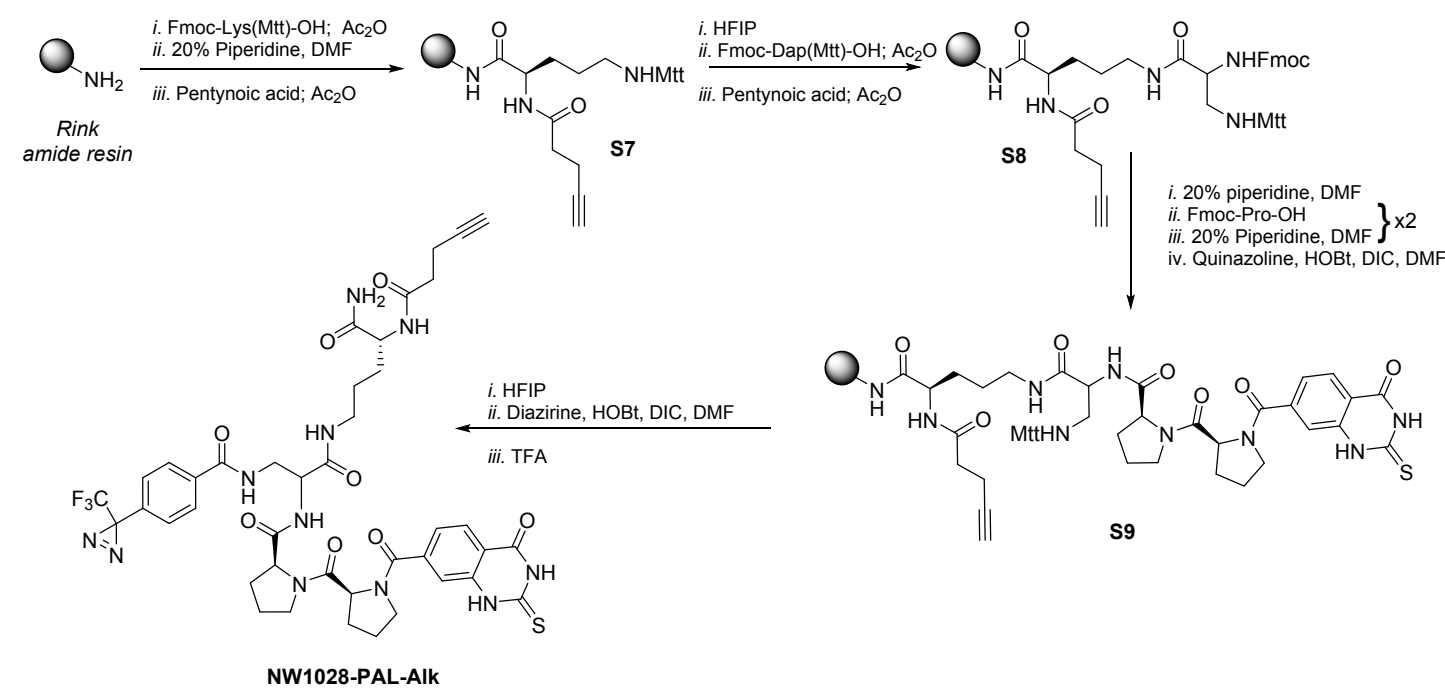

Supplementary Scheme S3: Synthesis of photoaffinity labelling analogue NW1028-PALAlk
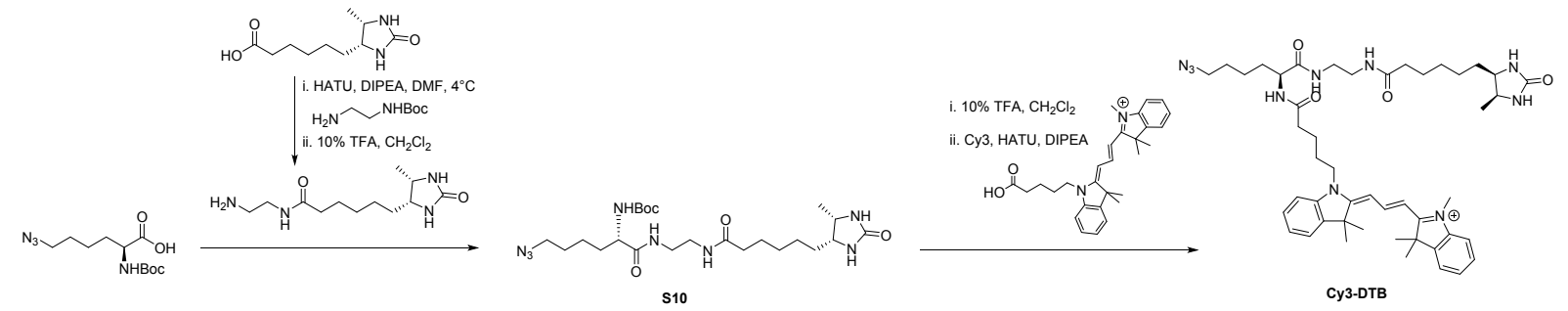

Supplementary Scheme S4: Synthesis of Cy3-DTB linker 


\section{Supplementary Methods}

\section{Docking with autodock vina general procedure}

Generation of ligand file: ligand files were obtained by drawing the desired ligands on Chemdraw 3D. All hydrogens were displayed and the structure was optimized both through MM2 and minimizing energy features of the software. The ligand file was then opened using AutodockTools and all the amide bonds were made rotatable. This ligand was use to generate the pdbqt file necessary to run autodock vina.

Opmization of search space: To generate the receptor, the crystal structure of the ND1L hexamer PDB: $5 D \mathrm{PI}^{1}$ was used. The residues from 26 to 460 were extracted to generate a ND1L monomer. This file was used to determine the search space used in autodock vina. Spacing was set to 1 angstrom and the following parameters were used as a search space: center_x $=-60.5$; center_y $=-14$; center_z $=10.0$; size_x $=28$; size_y $=16$; size_z $=16$; exhaustiveness $=100$.

\section{Chemical synthesis general procedures}

Anhydrous solvents were obtained by passing them through a commercially available alumina column (Innovative technology, MA). Solid phase syntheses were performed with NovaPEG Rink amide resin obtained from EMD Millipore. Peptide synthesis was performed using an automated peptide synthesizer (Intavis MultiPep instrument in $500 \mu \mathrm{L}$ fritted tubes.). LC-MS were recorded by using a Thermo Scientific Accela HPLC equipped with a Thermo $C 18(5 \mathrm{~cm}$ x $2.1 \mathrm{~mm}, 1.9 \mu \mathrm{m}$ particles) Hypersil gold column coupled with A: Surveyor MSQ Plus spectrometer or B: LCQ Fleet mass spectrometer (both ESI, Thermo Scientific). Method: linear elution gradient for $95 \% \mathrm{H} 2 \mathrm{O} 0.01 \%$ TFA to $90 \% \mathrm{MeCN} 0.01 \%$ TFA in 4 minutes at a flow rate of $0.75 \mathrm{~mL} / \mathrm{min}$. The MALDI spectra were measured using Bruker Daltonics Autoflex TOF/TOF spectrometer. Final compounds were purified by reverse-phase chromatography using a Biotage Isolera ONE equipped with a Biotage SNAP Cartridge KP-C18-HS (linear gradient from $100 \% \mathrm{H}_{2} \mathrm{O} 0.01 \%$ TFA to $100 \% \mathrm{MeCN} 0.01 \%$ TFA with a flow rate of $5 \mathrm{~mL} / \mathrm{min}$ ) or using an Agilent 1100 series HPLC equipped with DAD and with an Agilent ZORBAX Eclipse XDBC18 (4.6 x $250 \mathrm{~mm}, 5 \mu \mathrm{m})$ column. 


\section{Procedure 1: Resin loading}

The resin was washed with DMF and $\mathrm{CH}_{2} \mathrm{Cl}_{2}$ and treated with a pre-activated ( 5 min) solution of the corresponding Fmoc-protected amino acid (5 eq.), HATU (4 eq.), DIPEA (5 eq.), and 2,6-lutidine (7.5 eq.) for $2 \mathrm{~h}$ in NMP. Following the reaction, the resin was washed with DMF (3x), $\mathrm{CH}_{2} \mathrm{Cl}_{2}(3 \mathrm{x})$, DMF (3x) and $\mathrm{CH}_{2} \mathrm{Cl}_{2}(3 \mathrm{x})$. The resin was capped for at least one hour using acetic anhydride (5.3 eq.) and 2,6-lutidine (6.4 eq.) in DMF (150 $\mu \mathrm{L} / 5 \mathrm{mg}$ resin)

\section{Procedure 2. Capping}

To $10 \mathrm{mg}$ of NovaPEG Rink amide resin were added $100 \mu \mathrm{L}$ of capping mixture $(9.2 \mathrm{~mL}$ of acetic anhydride and $13 \mathrm{~mL}$ of 2,6 lutidine in $188 \mathrm{~mL}$ of DMF). After $5 \mathrm{~min}$, the resin was washed with $2 \times 250 \mu \mathrm{L}$ of DMF.

\section{Procedure 3: Fmoc deprotection}

To $5 \mathrm{mg}$ of NovaPEG Rink amide resin were added $200 \mu \mathrm{L}$ of $20 \%$ piperidine solution in DMF. After $2 \mathrm{~min}$, the resin was washed with $6 \times 300 \mu \mathrm{L}$ DMF and the sequence was repeated a second time for $4 \mathrm{~min}$. Finally, the resin was washed with $6 \times 300 \mu \mathrm{L}$ of DMF and $6 \times 300 \mu \mathrm{L}$ of $\mathrm{CH}_{2} \mathrm{Cl}_{2}$ and the washing cycle was repeated a second time.

\section{Procedure 4: PEG and building block attachment on resin}

Using HCTU or HATU activation: To a solution of $0.08 \mathrm{mmol}$ (4.0 equiv) of amino acid in NMP $(1 \mathrm{~mL})$ were added $140 \mu \mathrm{L}(0.07 \mathrm{mmol}, 3.5$ equiv) of HCTU or HATU (0.5 M) in NMP followed by $67 \mu \mathrm{L}$ of base solution [DIPEA $1.2 \mathrm{M}(0.25 \mathrm{mmol}, 4.0$ equiv) and 2,6 lutidine $1.8 \mathrm{M}(0.38$ mmol, 6.0 equiv) in NMP]. The mixture was activated for $5 \mathrm{~min}$ at room temperature, and then added to $40 \mathrm{mg}$ of resin ( $0.02 \mathrm{mmol}, 1.0$ equiv). The reaction mixture was shaken for 2 hours and subsequently the resin was washed with $6 \times \mathrm{DMF}$ and $6 \times \mathrm{CH}_{2} \mathrm{Cl}_{2}$.

Using HOBt/DIC activation: The corresponding carboxylic acid $(0.01 \mathrm{mmol}, 5.0$ equiv) was dissolved in $200 \mu \mathrm{L}$ of NMP and HOBt (1.5 mg, $0.01 \mathrm{mmol}, 5.0$ equiv) followed by DIC (4.7 $\mu \mathrm{L}$, $0.03 \mathrm{mmol}, 15.0$ equiv) were added. The mixture was activated for $15 \mathrm{~min}$, then added to the corresponding resin (10 mg, $0.002 \mathrm{mmol}, 1.0$ equiv) and the reaction was shaken for 12 hours. Finally, the resin was washed with $6 \times 250 \mu \mathrm{L}$ of DMF and $6 \times 250 \mu \mathrm{L} \mathrm{CH}_{2} \mathrm{Cl}_{2}$.

\section{Procedure 5: Mtt deprotection}

$10 \mathrm{mg}$ of resin were treated with $200 \mu \mathrm{L}$ of a HOBt solution $(122 \mathrm{mg}$ in $10 \mathrm{~mL}$ of $50 \%$ hexafluoroisopropanol in 1,2 dichoroethane) for $3 \mathrm{~min}$. The reaction was repeated 4 times with a $\mathrm{CH}_{2} \mathrm{Cl}_{2}$ wash after the second cycle.

\section{Procedure 6: Biotin coupling}

$10 \mathrm{mg}$ of resin $(2.0 \mu \mathrm{mol}, 1.0$ equiv) were treated with Biotin-OSu ( $1.3 \mathrm{mg}, 4.0 \mu \mathrm{mol}, 2.0$ equiv) in and 2,6-lutidine (1.0 $\mu \mathrm{L}, 8.0 \mu \mathrm{mol}, 4.0$ equiv) in solution in $200 \mu \mathrm{L}$ of NMP. The 
reaction was shaken at room temperature for a minimum of 10 hours and then washed with 4 $\times 250 \mu \mathrm{L}$ of DMF and $4 \times 250 \mu \mathrm{L}$ of $\mathrm{CH}_{2} \mathrm{Cl}_{2}$

\section{Procedure 7: Cleavage from the resin}

$10 \mathrm{mg}$ of resin were treated with $200 \mu \mathrm{L}$ TFA for 1 hour. The resin was washed with $3 \times 300$ $\mu \mathrm{L}$ of a mixture of $1: 1$ water/acetonitrile. The resulting solution was freeze-dried for further HPLC purification.

\section{Procedure 8: In solution synthesis of Cy3-DTB}

Amide bond formation: The carboxylic acid (1.0 equiv.) and HATU (1.1 equiv.) were dissolved in DMF (3mL), DIPEA (3.0 equiv.) was added to the solution. The acid activation was carried out $5 \mathrm{~min}$ in an ice bath. The amine (1.0 equiv.) was dissolved in DMF $500 \mu \mathrm{L}$ and added to the reaction mixture. The reaction was stirred for $15 \mathrm{~min}$ at $0^{\circ} \mathrm{C}$. LC-MS analysis of an aliquot revealed full conversion.

The reaction was quenched by addition of water $(10 \mathrm{~mL})$ and extracted 3 times with $\mathrm{CH}_{2} \mathrm{Cl}_{2}$ $(20 \mathrm{~mL})$. The organic layers were combined, dried with sodium sulfate and concentrated. The product was purified by reverse phase chromatography.

Boc deprotection: The compound was dissolved in dichloromethane and cooled down to $0^{\circ} \mathrm{C}$. TFA ( $10 \%$ volume of dichloromethane) was added to the solution and the reaction was carried out for 2 hours at $0^{\circ} \mathrm{C}$. The reaction was monitored by both TLC and LC-MS. Once conversion was judged complete, the solvent were evaporated and the compound was re-dissolved in $\mathrm{CH}_{2} \mathrm{Cl}_{2}$ and evaporated to dryness twice and finally dried on high vacuum. The obtained compound was used immediately in the next steps of the synthesis.

The final compound Cy3-DTB was purified by reverse phase HPLC. 


\section{Analytical data of synthesized compounds}
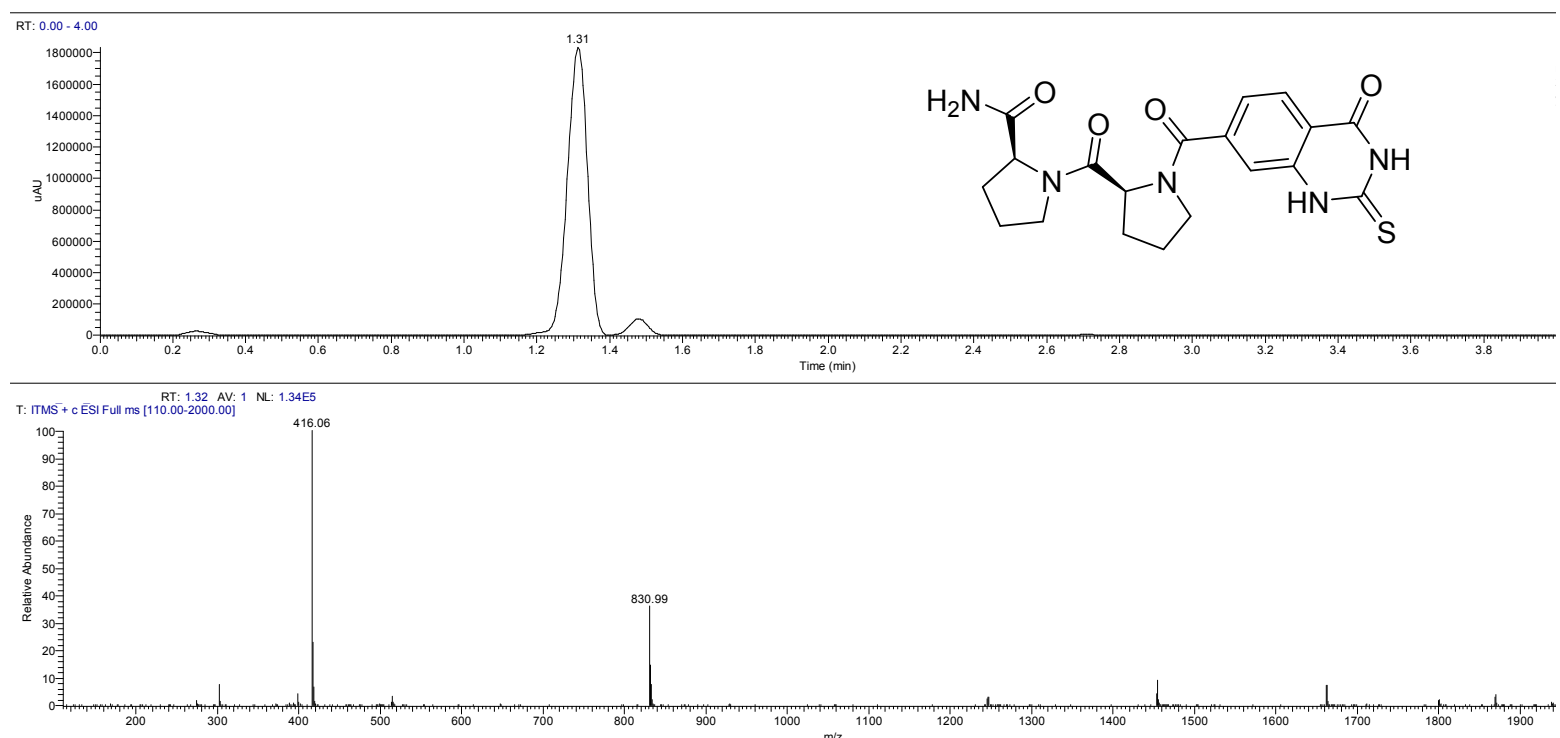

LC-MS trace of compound NW 1028: $[\mathrm{M}+\mathrm{H}]^{+}$expected: $416.48 \mathrm{Da}$ found: $416.06 \mathrm{Da}$.

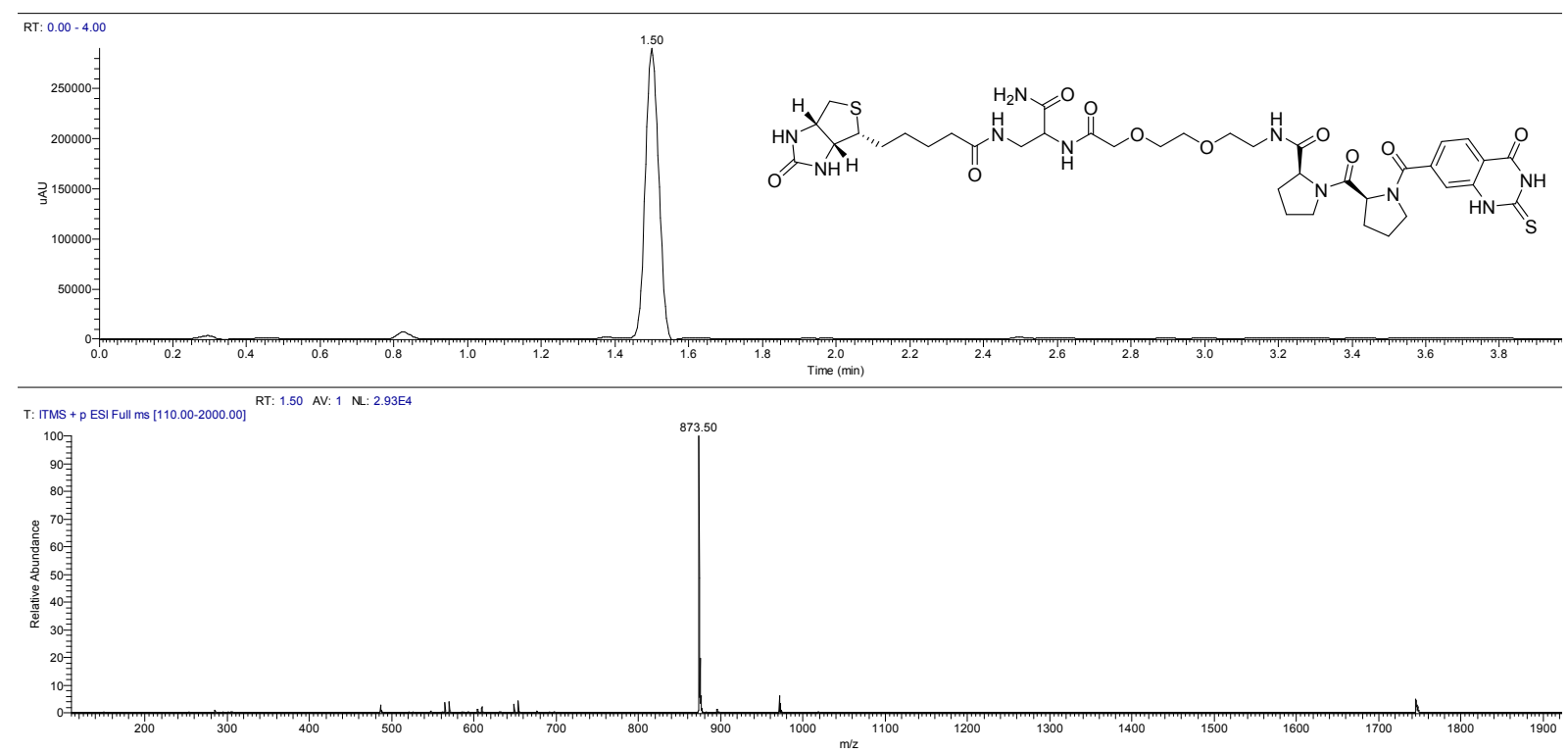

LC-MS trace of compound NW 1028-biotin: $[\mathrm{M}+\mathrm{H}]^{+}$expected: $873.34 \mathrm{Da}$ found: $873.50 \mathrm{Da}$ 

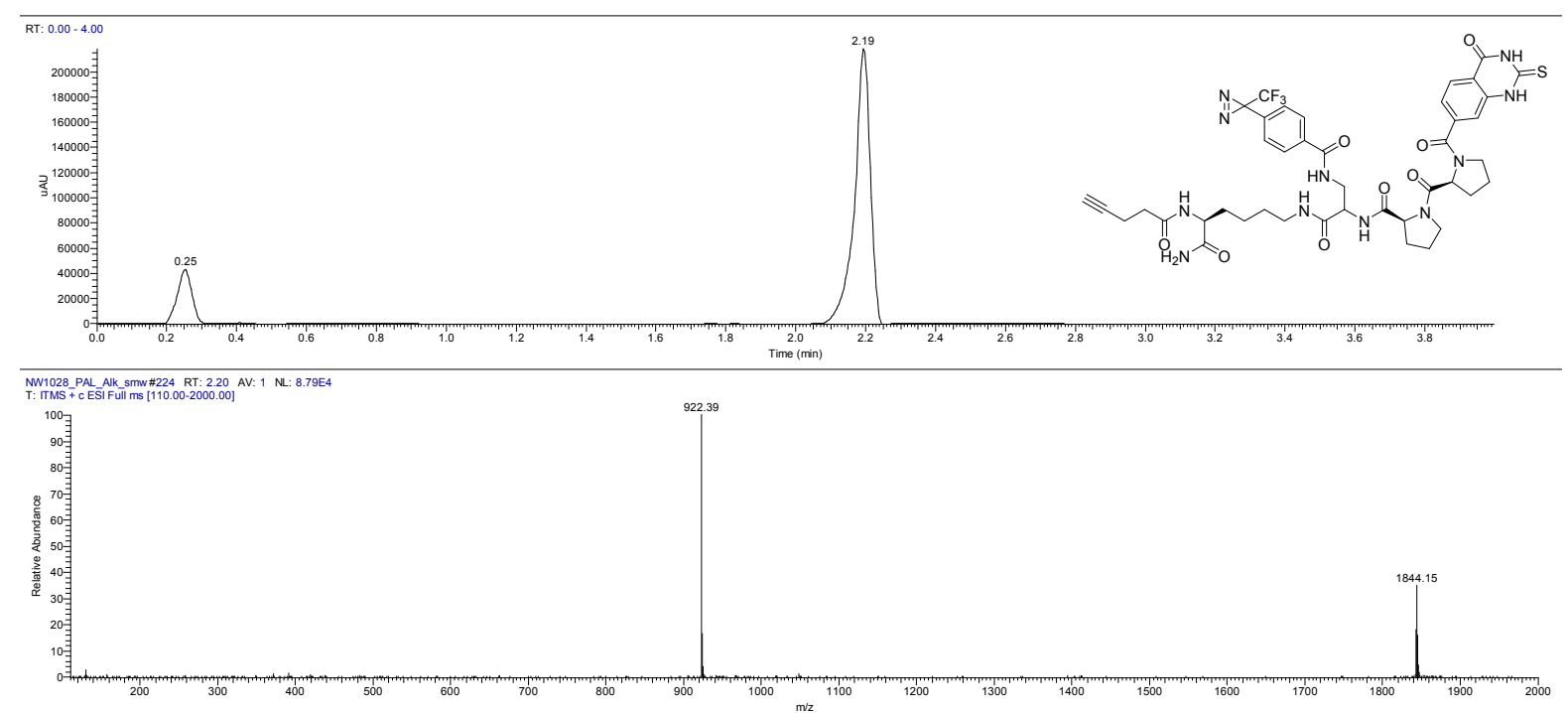

LC-MS trace of NW1028-PAL-Alk: [M+H] ${ }^{+}$expected:922.33 Da; $[\mathrm{M}+\mathrm{H}]^{+}$found $922.39 \mathrm{Da}$
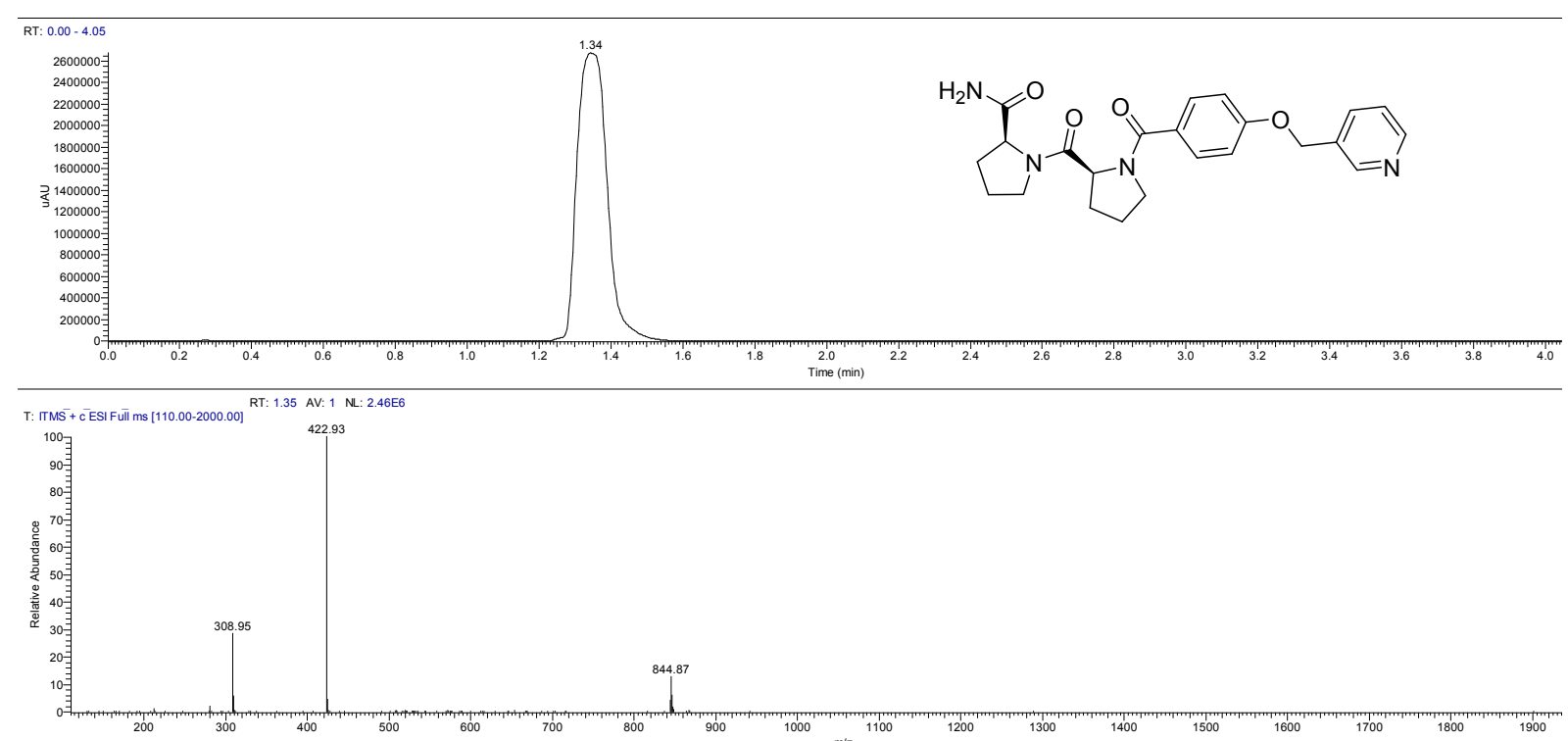

LC-MS trace of compound NW $1029:[\mathrm{M}+\mathrm{H}]^{+}$expected: 422.49 Da found: $422.93 \mathrm{Da}$ 


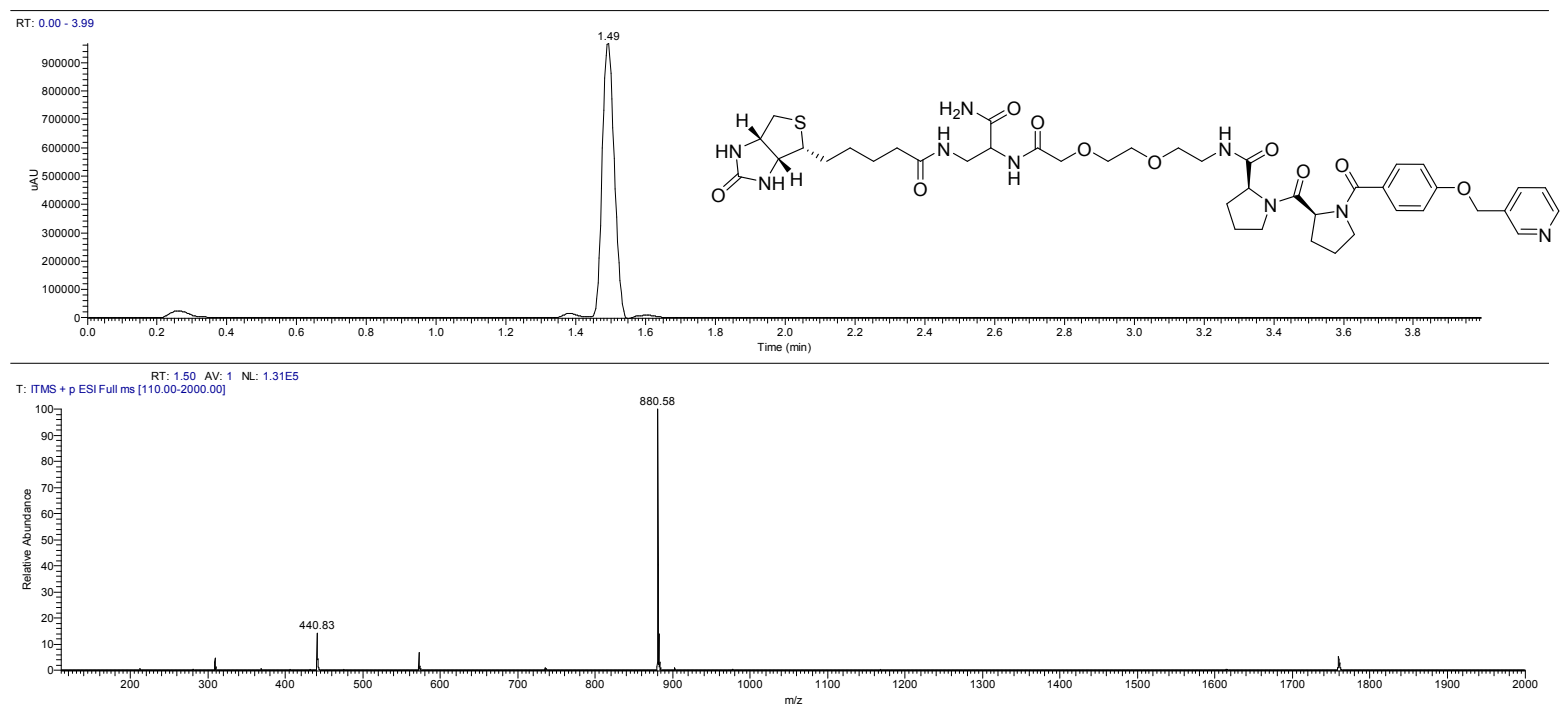

LC-MS trace of compound NW 1029-biotin: $[\mathrm{M}+2 \mathrm{H}]^{2+}$ expected: $440.70 \mathrm{Da}$ found: 440.83

Da; $[\mathrm{M}+\mathrm{H}]^{+}$expected: $880.40 \mathrm{Da}$ found: $880.58 \mathrm{Da}$.

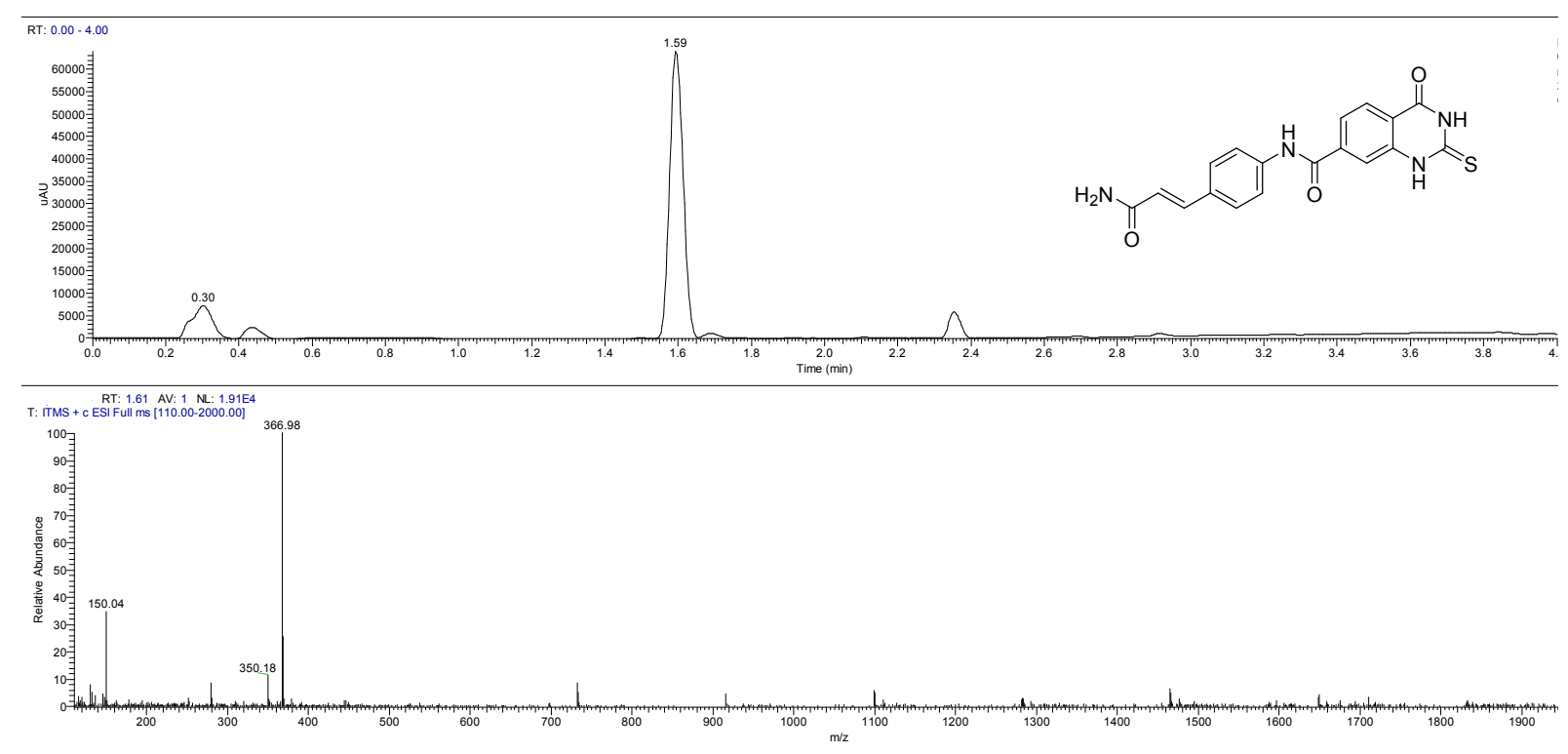

LC-MS trace of NW 1030: [M+H] $]^{+}$expected: 366.40 Da found: 366.98 Da. 

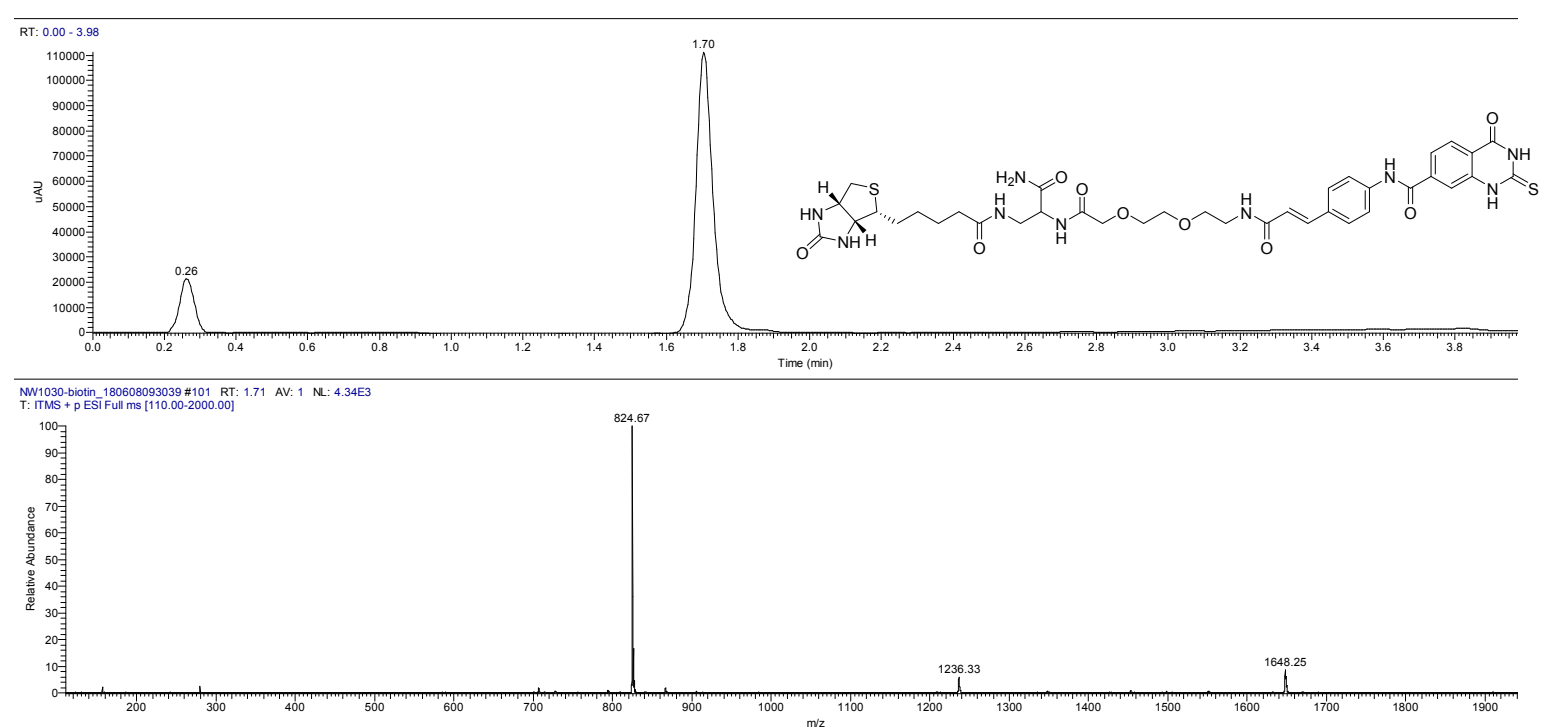

LC-MS trace of compound NW 1030-biotin: $[\mathrm{M}+\mathrm{H}]^{+}$expected: 824.29 Da found: 824.67 Da.

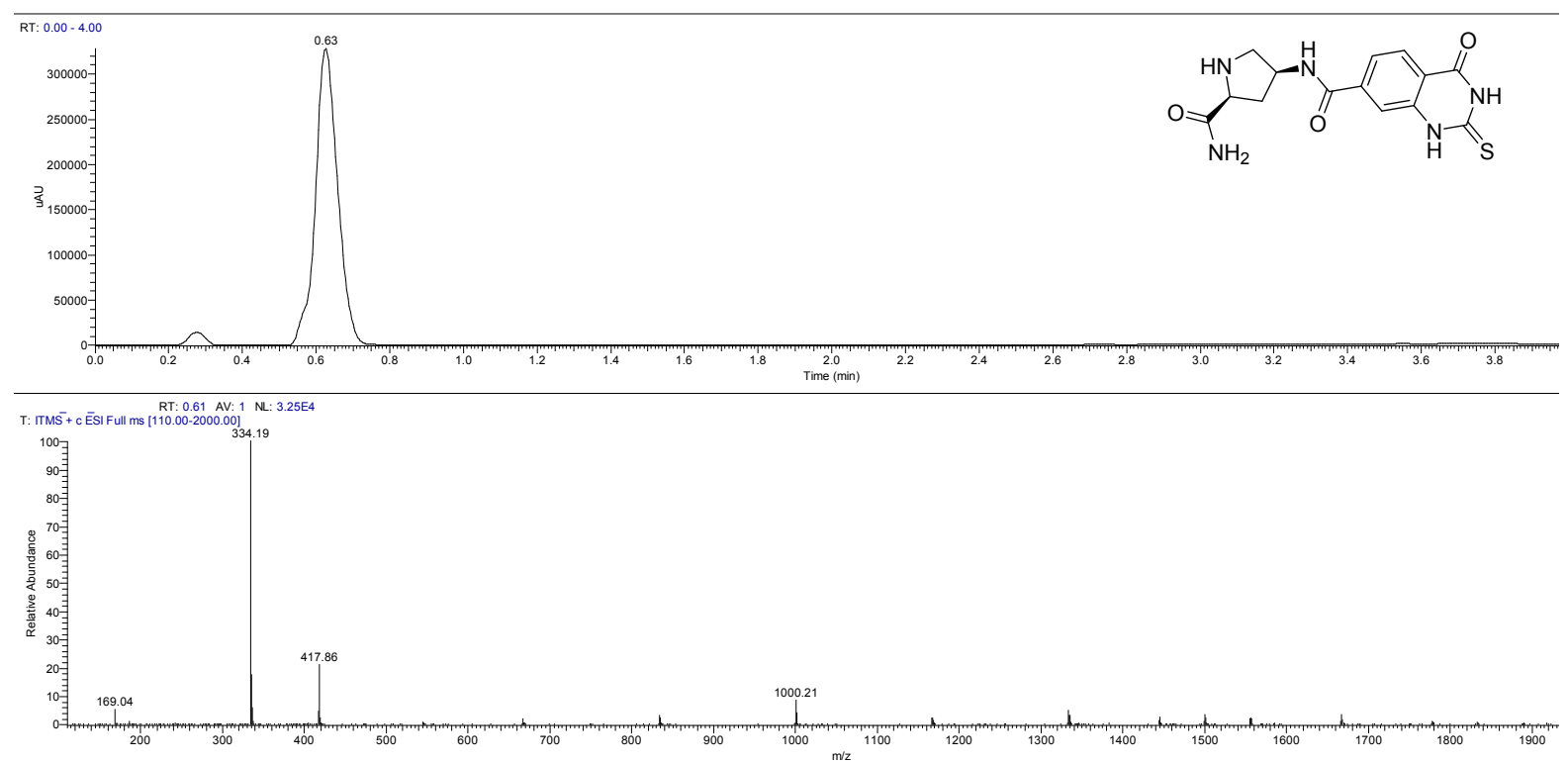

LC-MS trace of NW 1047: [M+H] $]^{+}$expected: 334.10 Da found: 334.19 Da 


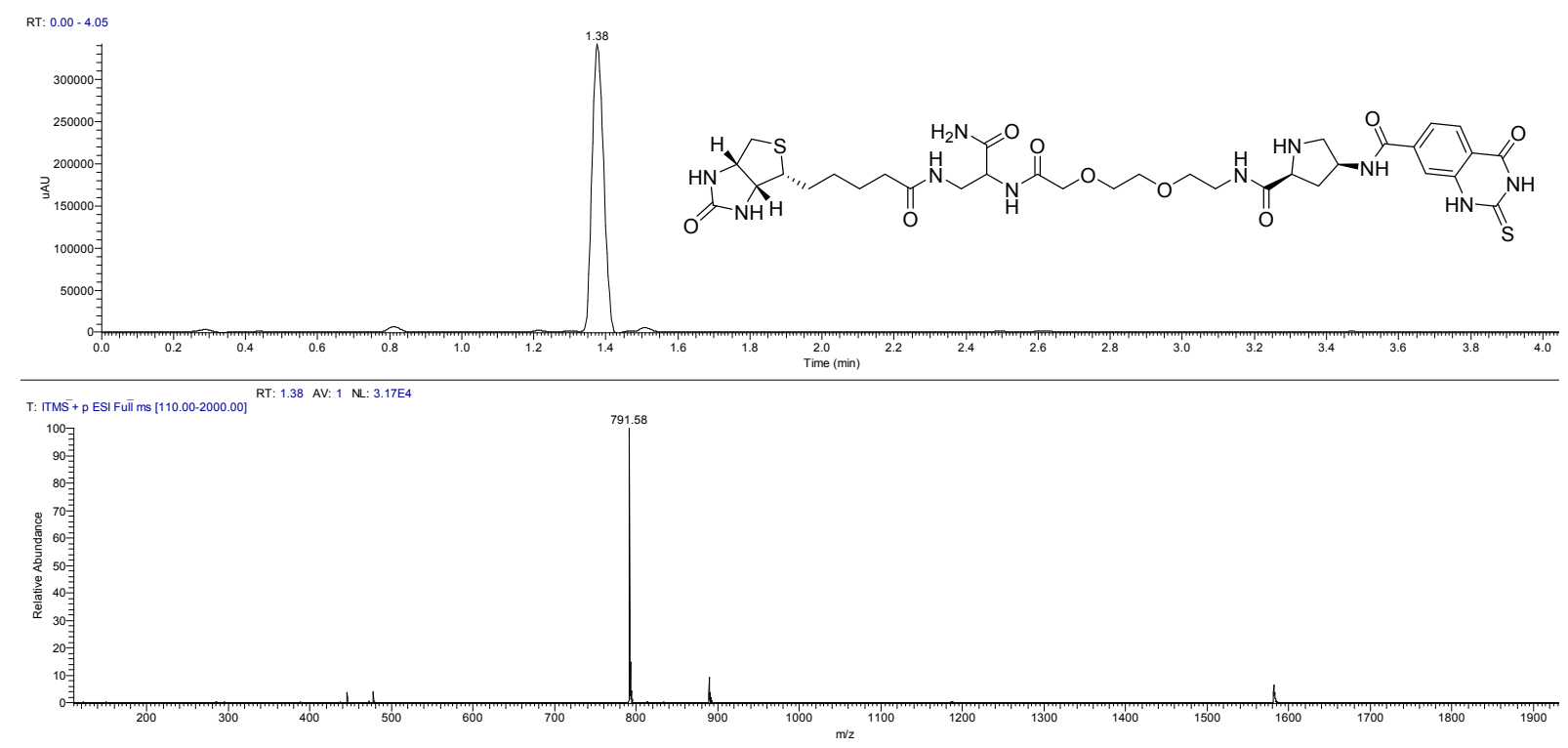

LC-MS trace of compound NW 1047-biotin: $[\mathrm{M}+\mathrm{H}]^{+}$expected: 791.30 Da found: 791.58 Da.
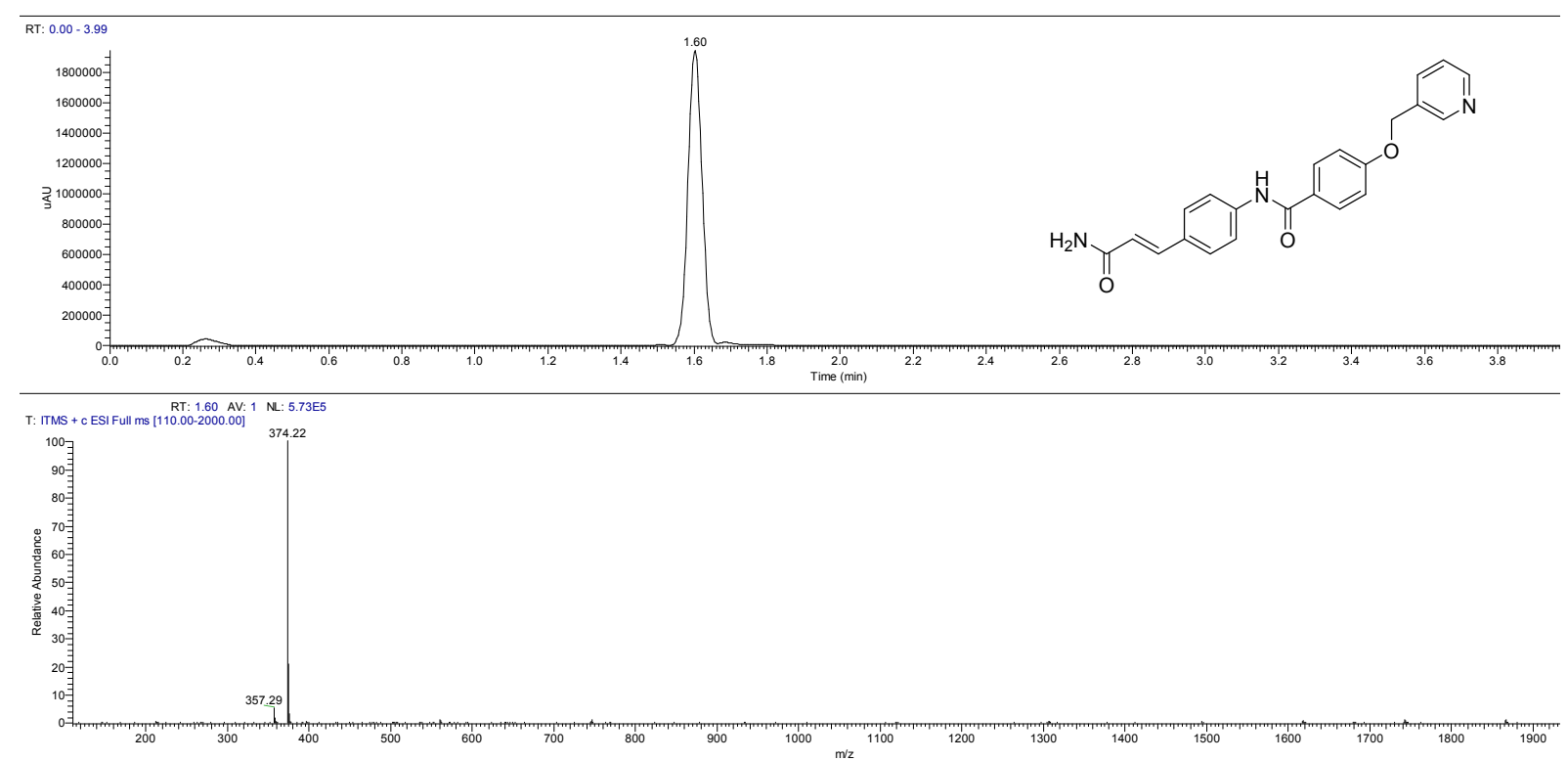

LC-MS trace of NW 1049: [M+H] $]^{+}$expected: 374.41 Da found: 374.22 Da. 


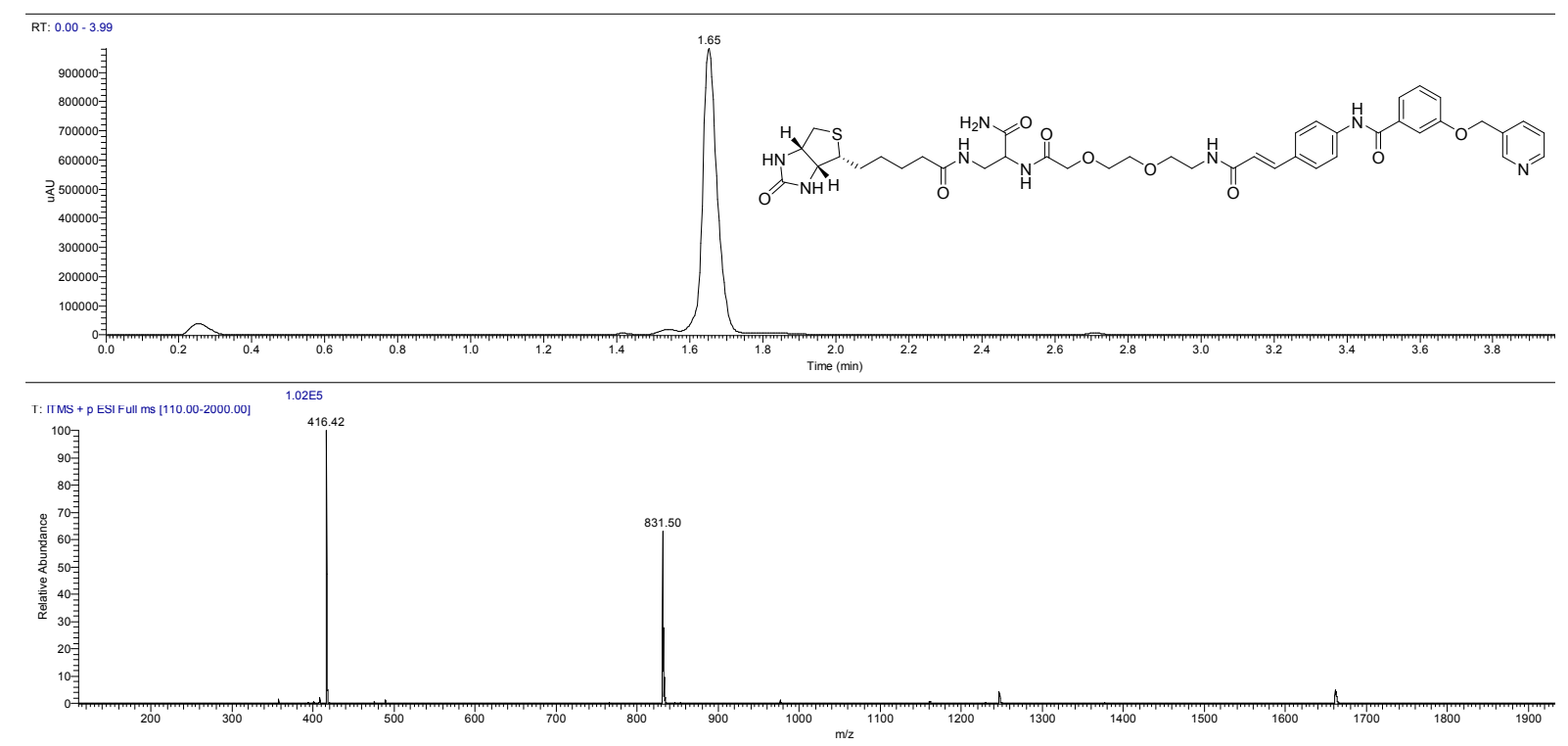

LC-MS trace of compound NW 1049-biotin: $[\mathrm{M}+2 \mathrm{H}]^{2+}$ expected: $416.18 \mathrm{Da}$ found: 416.42 $\mathrm{Da} ; \mathrm{M}+\mathrm{H}]^{+}$expected: 831.96 Da found: $831.50 \mathrm{Da}$.

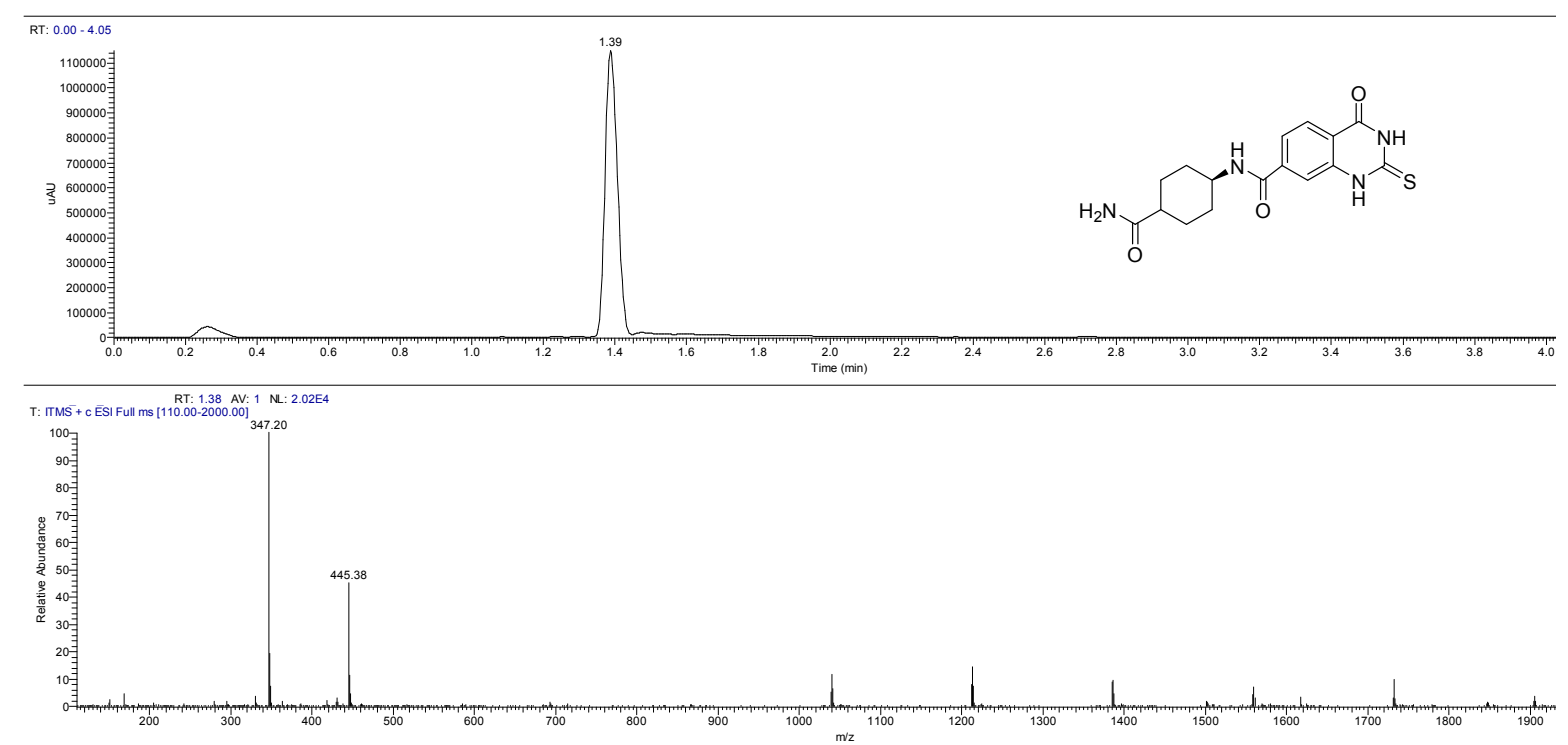

LC-MS trace of NW 1052: [M+H] $]^{+}$expected: 347.12 Da found: $347.20 \mathrm{Da} ;\left[\mathrm{M}+\mathrm{H}+\mathrm{C}_{2} \mathrm{~F}_{3} \mathrm{O}\right]^{+}$ expected 445.44 Da found 445.38 Da. 


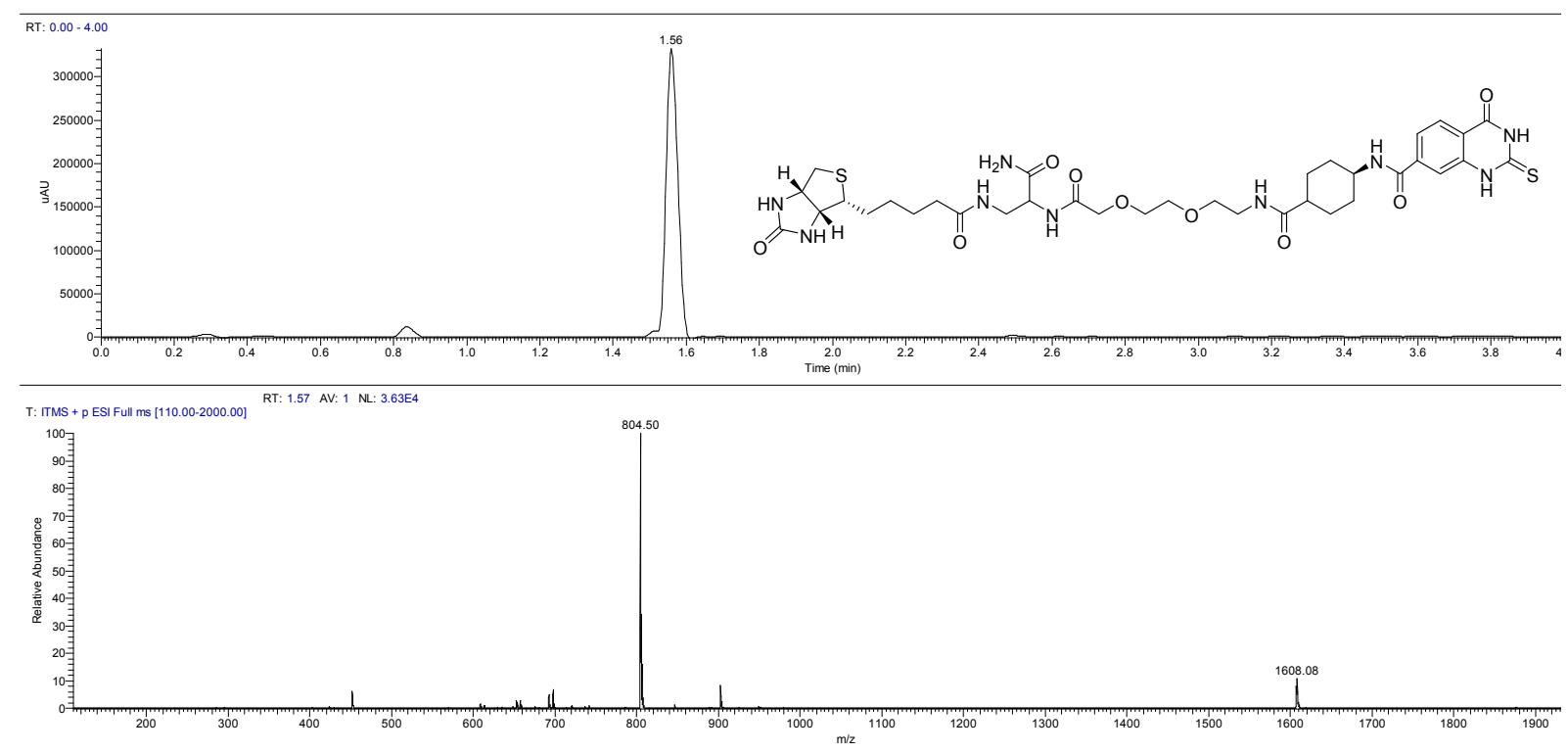

LC-MS trace of compound NW 1052-biotin: $[\mathrm{M}+\mathrm{H}]^{+}$expected: $804.95 \mathrm{Da}$ found: $804.50 \mathrm{Da}$

ILCOFLEETPCIdatal...IChacquesINW1080 21066/2018 22:05:24
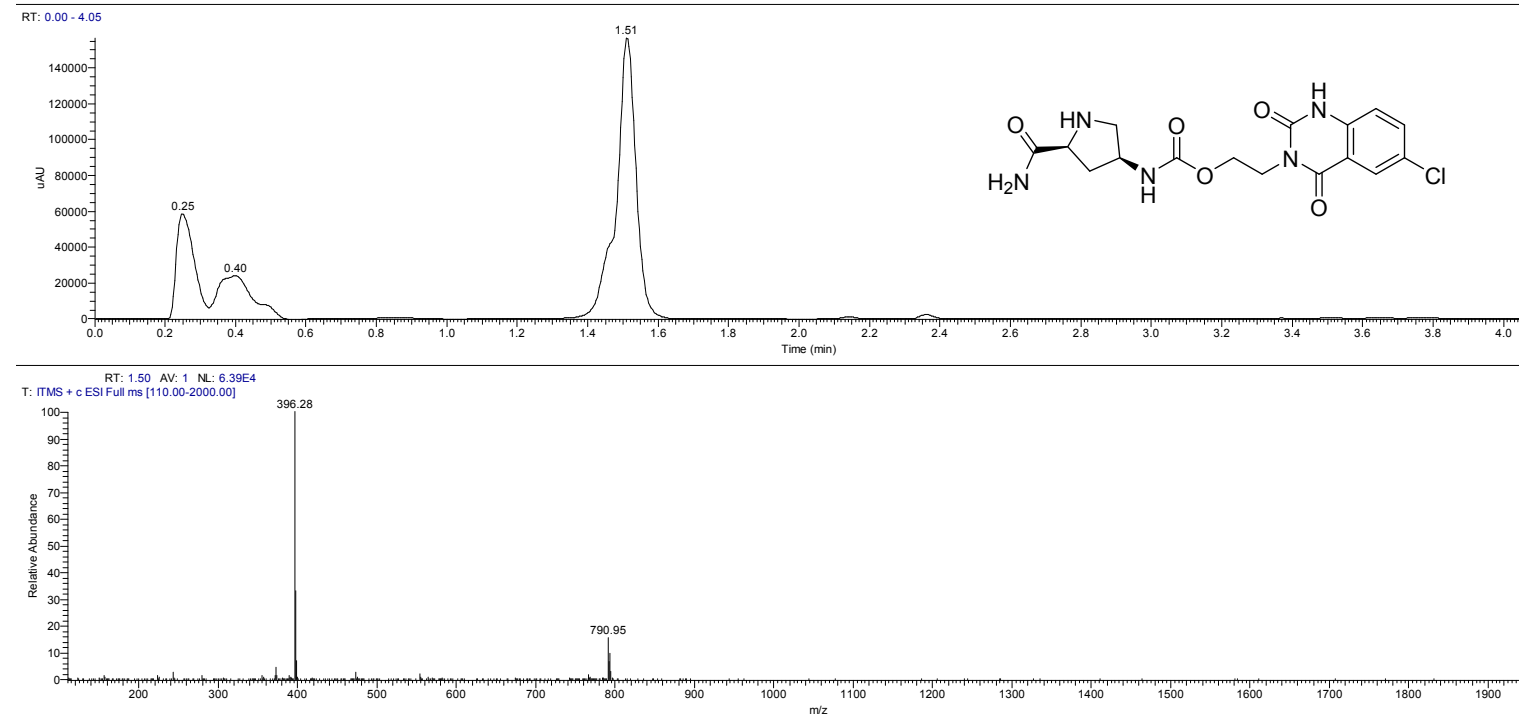

LC-MS trace of NW 1080: [M+H] $]^{+}$expected: 396.11 Da found: 396.28 Da. 


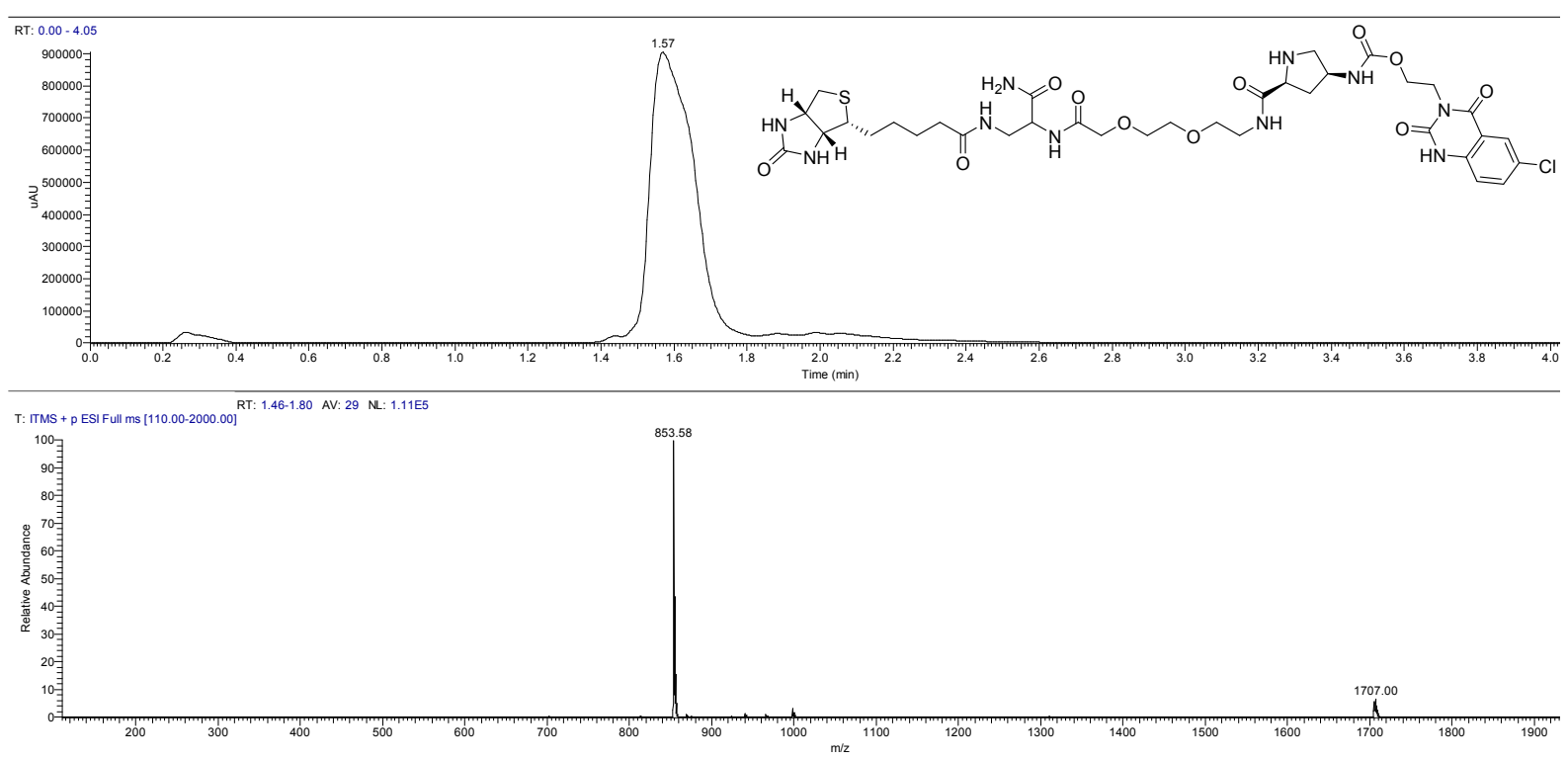

LC-MS trace of compound NW 1080-biotin: $[\mathrm{M}+\mathrm{H}]^{+}$expected: 853.31 Da found: $853.58 \mathrm{Da}$.
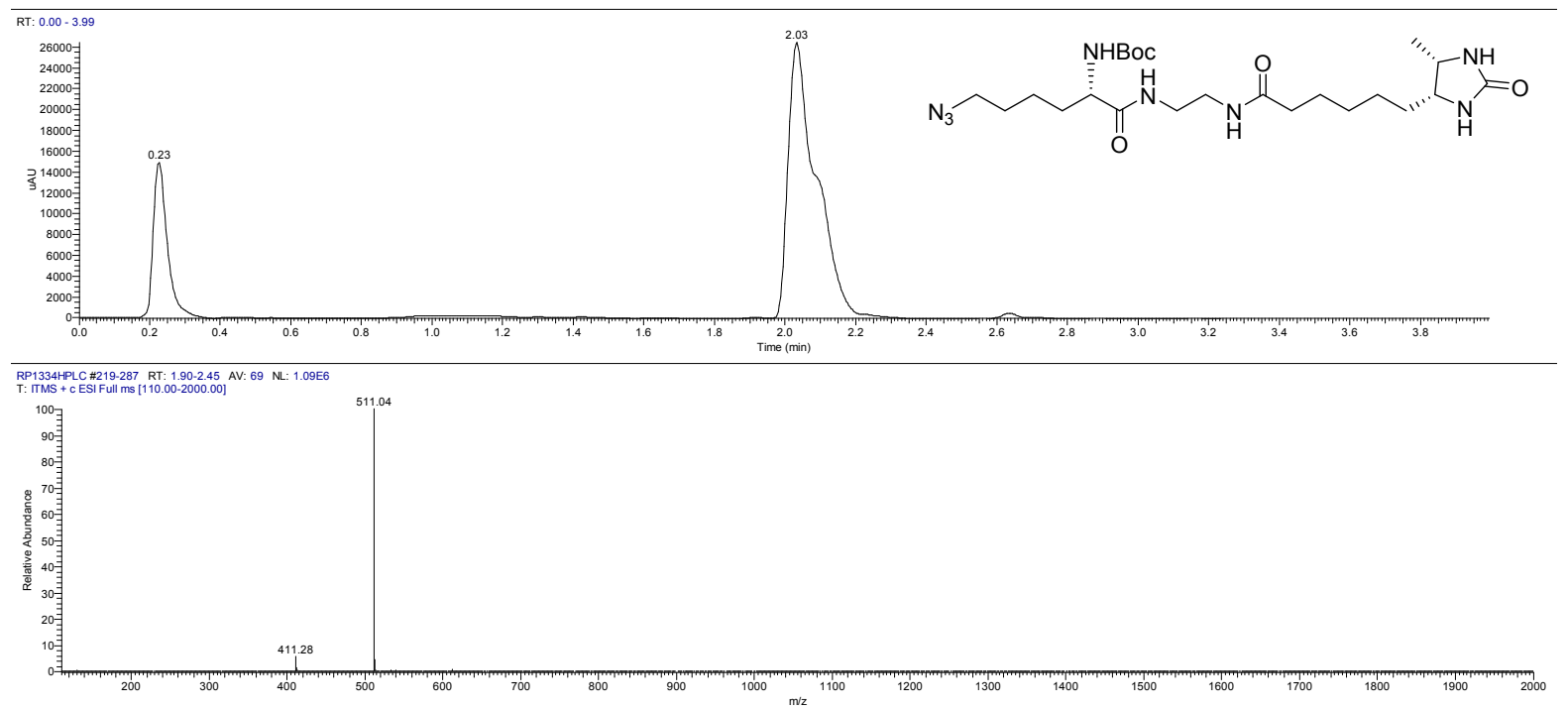

LC-MS trace of intermediate S10: $[\mathrm{M}+\mathrm{H}]^{+}$expected: $511.34 \mathrm{Da}$ found: $511.04 \mathrm{Da}$. Also observed Boc deprotection on LC-MS by TFA in solvent, $[\mathrm{M}+\mathrm{H}]^{+}$expected: $411.28 \mathrm{Da}$; found 411.28 Da 

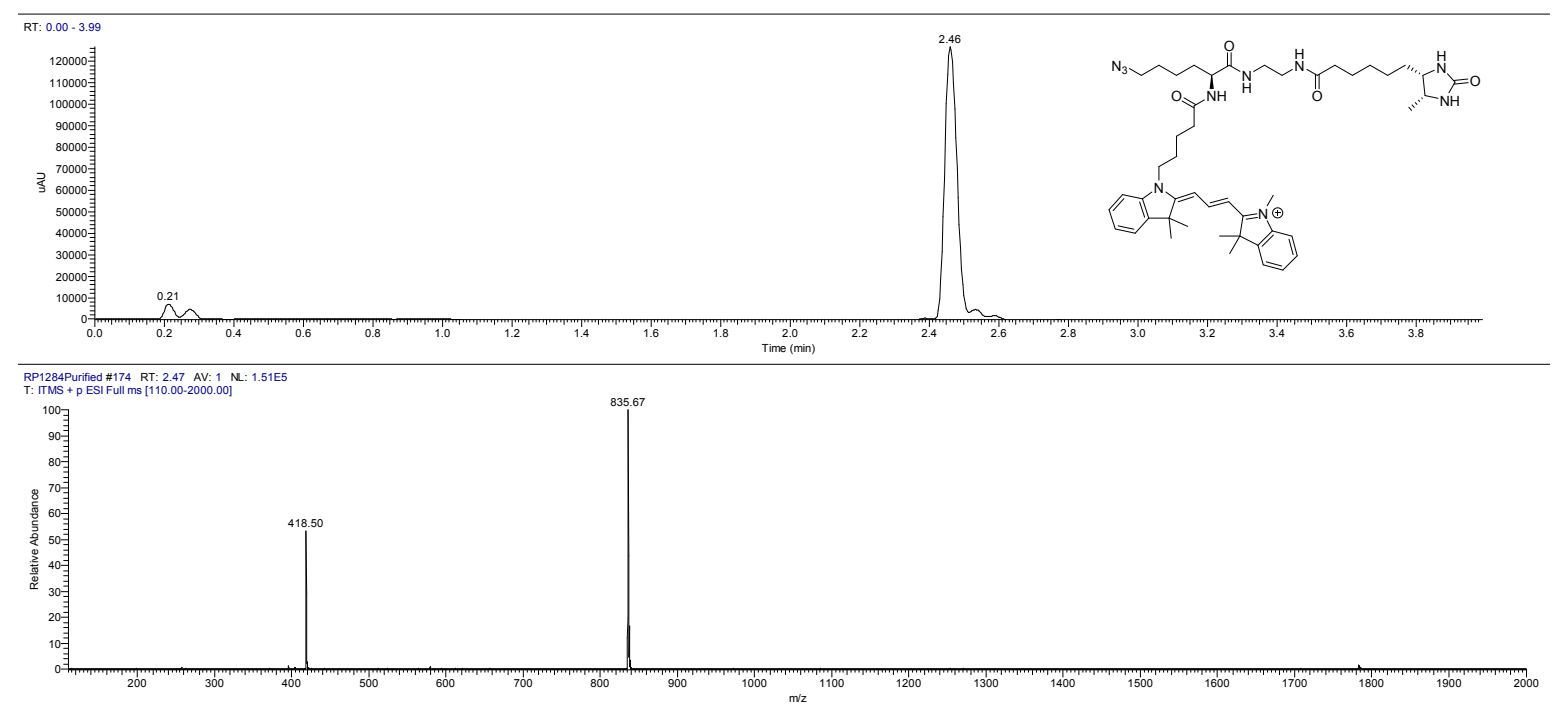

LC-MS trace of Cy3-DTB. [M] ${ }^{+}$expected: 835.53 Da found: $835.67 \mathrm{Da} .[\mathrm{M}+\mathrm{H}]^{2+}$ expected: 418.27 Da, found 418.50 Da. 


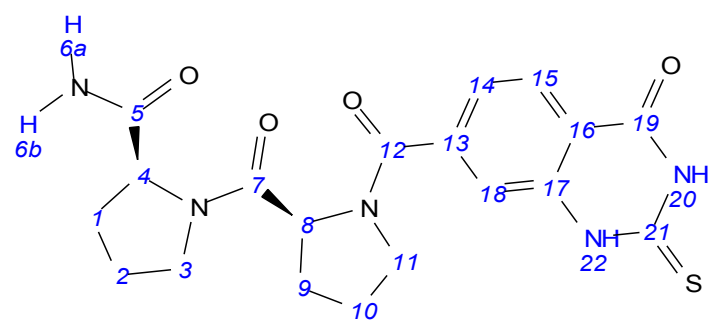

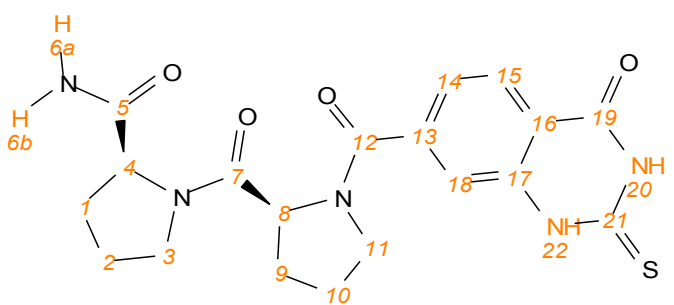

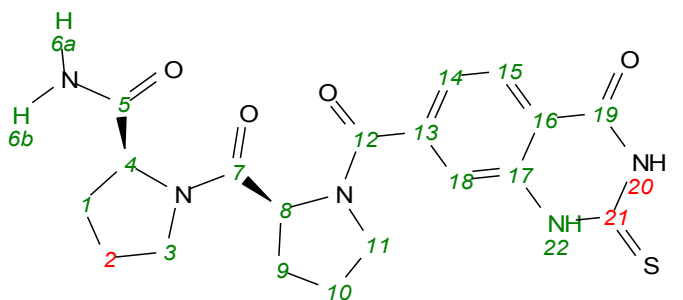

NMR of NW1028 Compound NW1028 exists under 3 different rotamers that can be seen in all the NMR spectras. The three rotamers are color-coded and the signals corresponding to each rotamer's atoms is labeled on the following spectras (Supplementary figure 20 to 25).

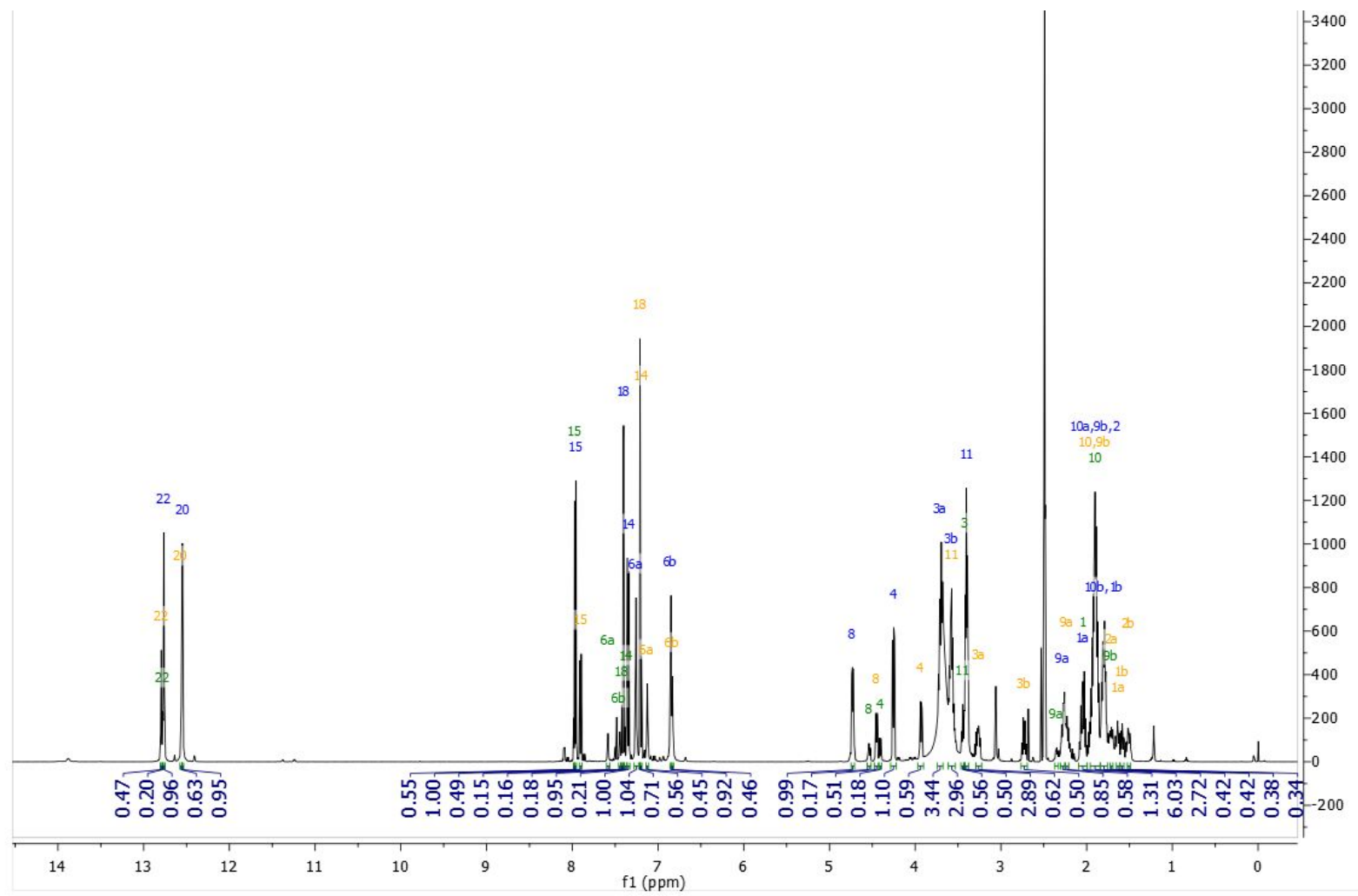

${ }^{1} \mathrm{H}$ NMR of NW1028 (500 MHz, DMSO-d6) 


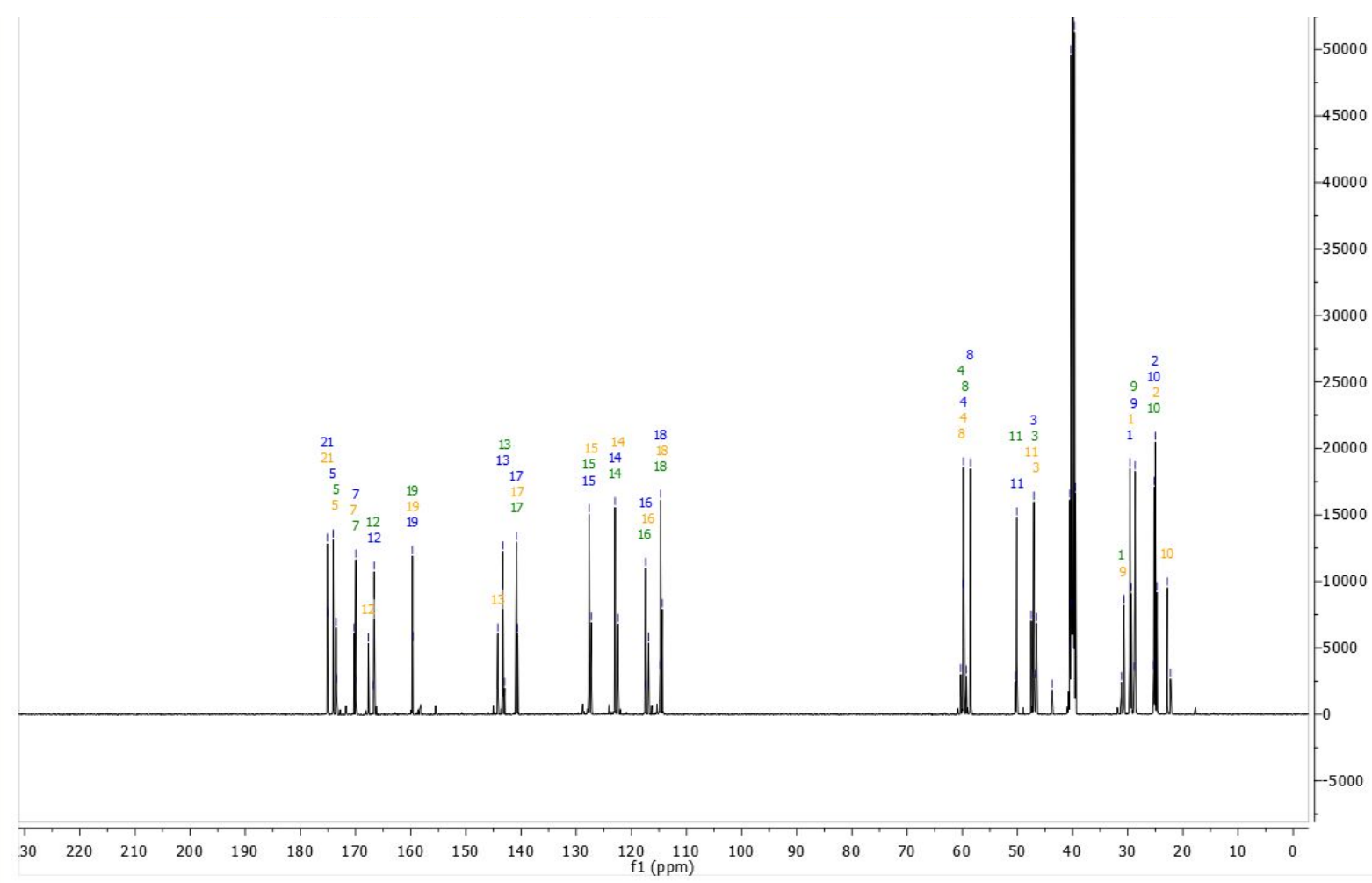

Supplementary Figure 13: ${ }^{13} \mathrm{C}$ NMR of NW1028 $(500 \mathrm{MHz}, \mathrm{DMSO}-\mathrm{d} 6)$

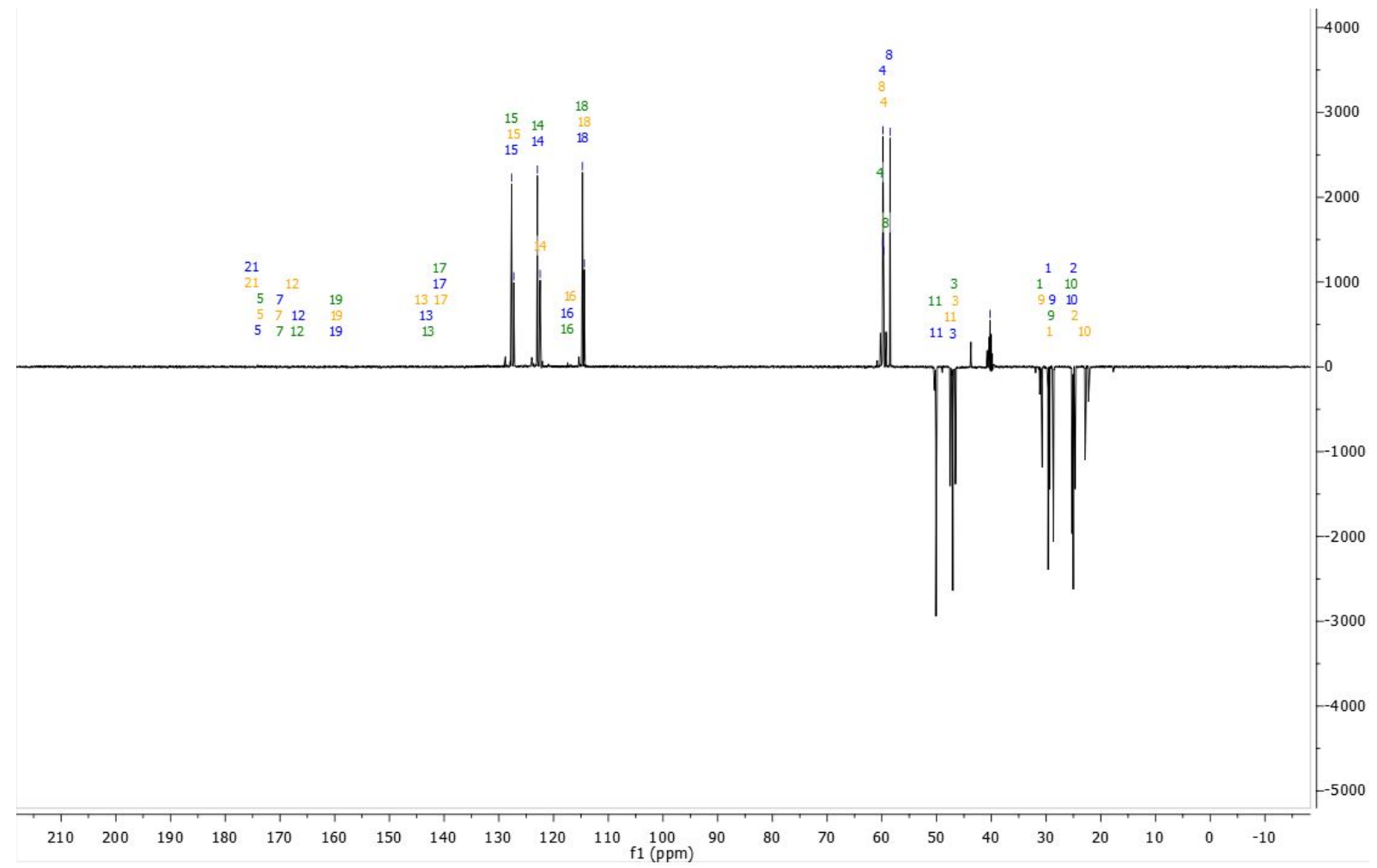

Supplementary Figure 14: DEPT $135{ }^{13} \mathrm{C}$ of NW1028 (500 MHz, DMSO-d6) 


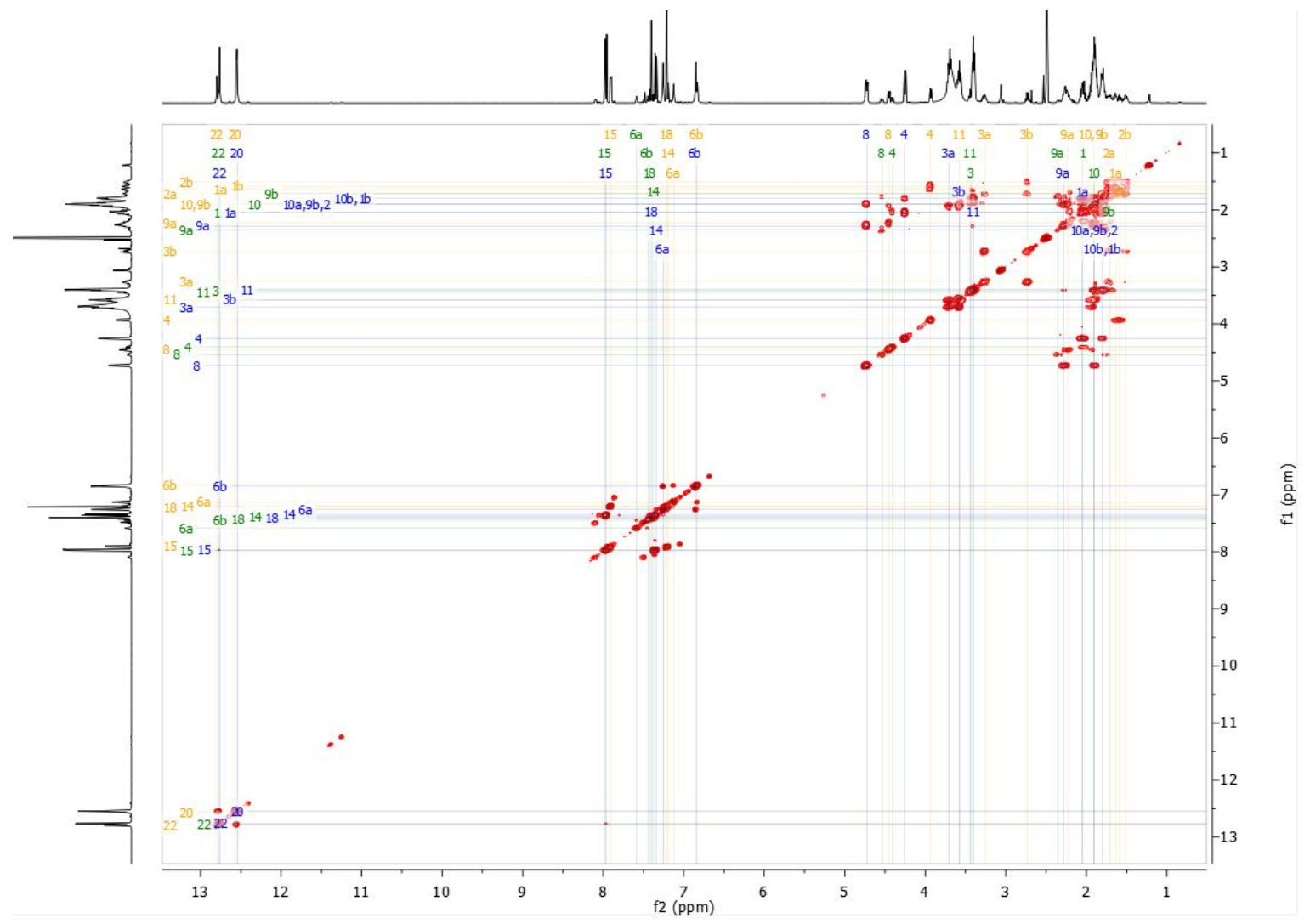

COSY ${ }^{1} \mathrm{H}$ of NW1028 (500 MHz, DMSO-d6) 


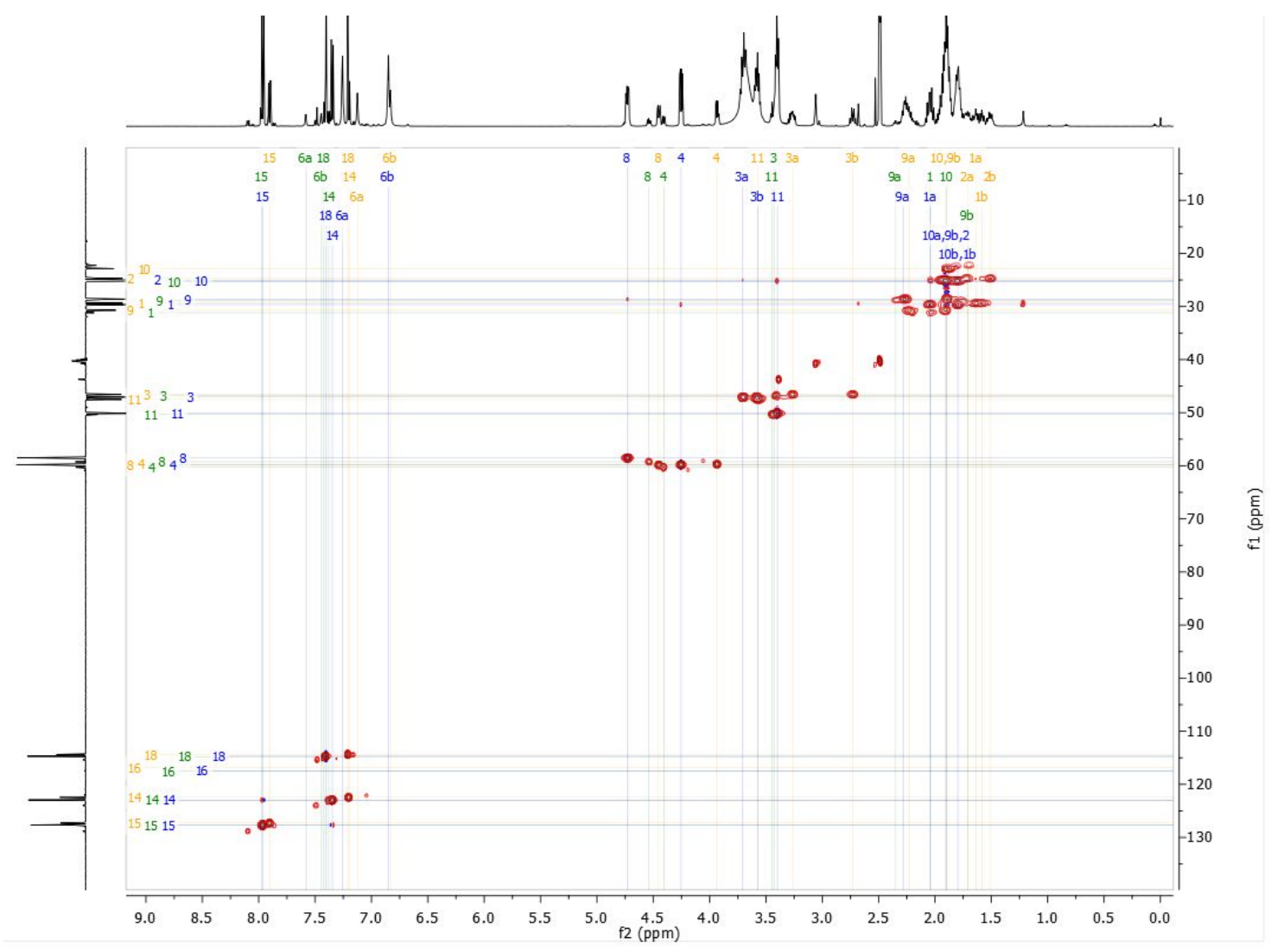

HSQC of NW1028 (500 MHz, DMSO-d6) 


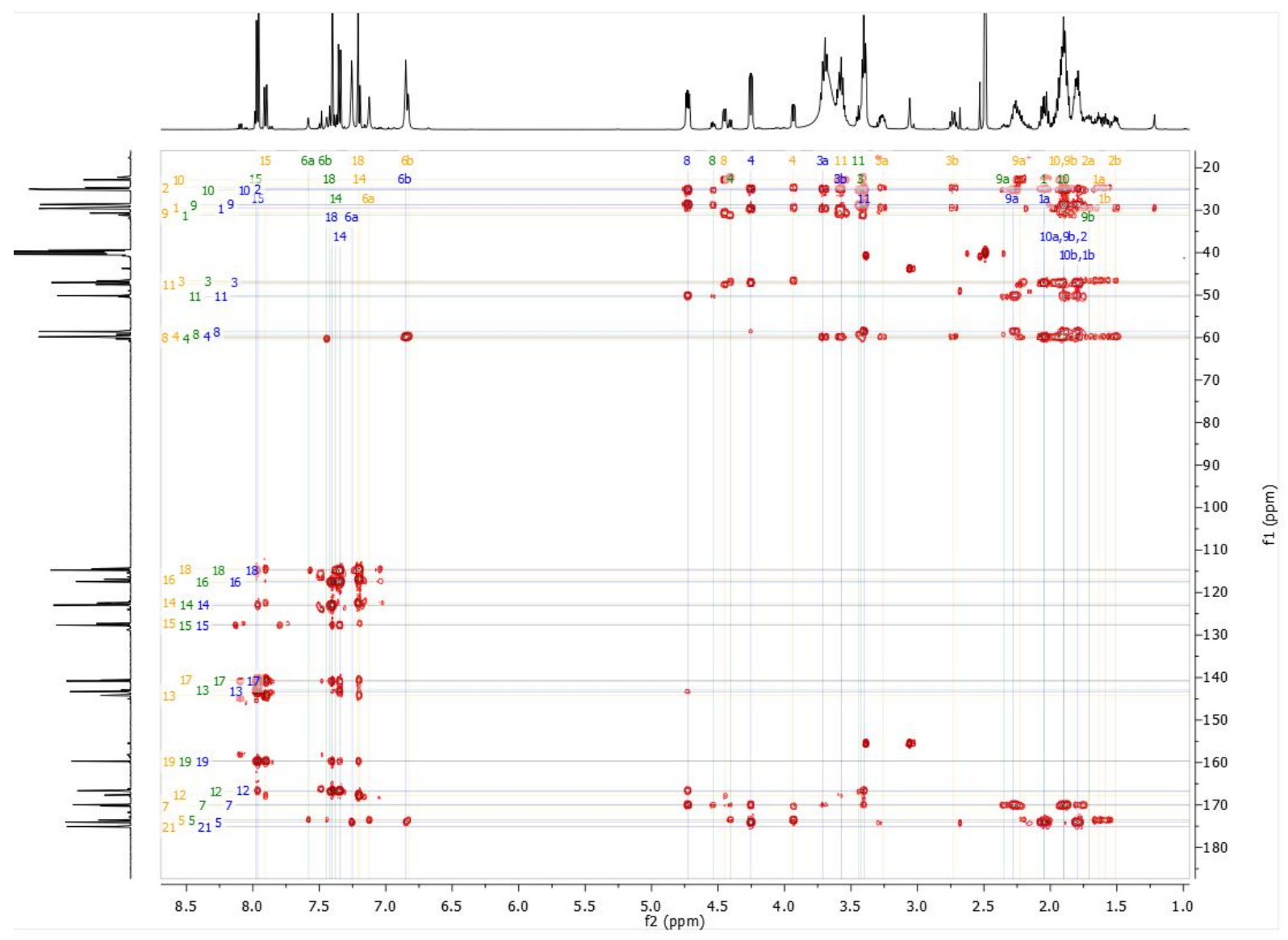

HSQC of NW1028 (500 MHz, DMSO-d6) 


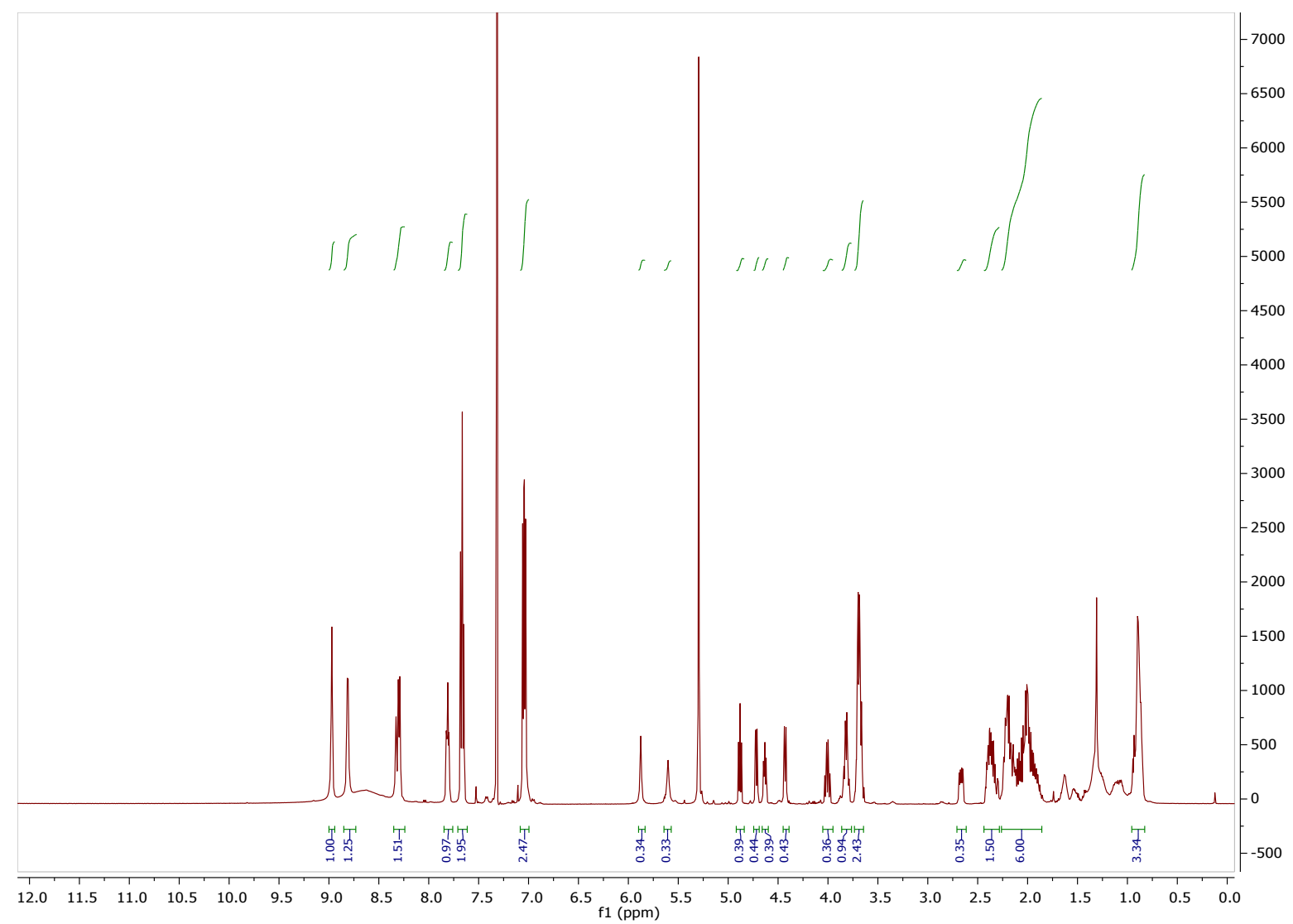

${ }^{1} \mathrm{H}$ NMR of NW1029 (500 MHz, DMSO-d6)

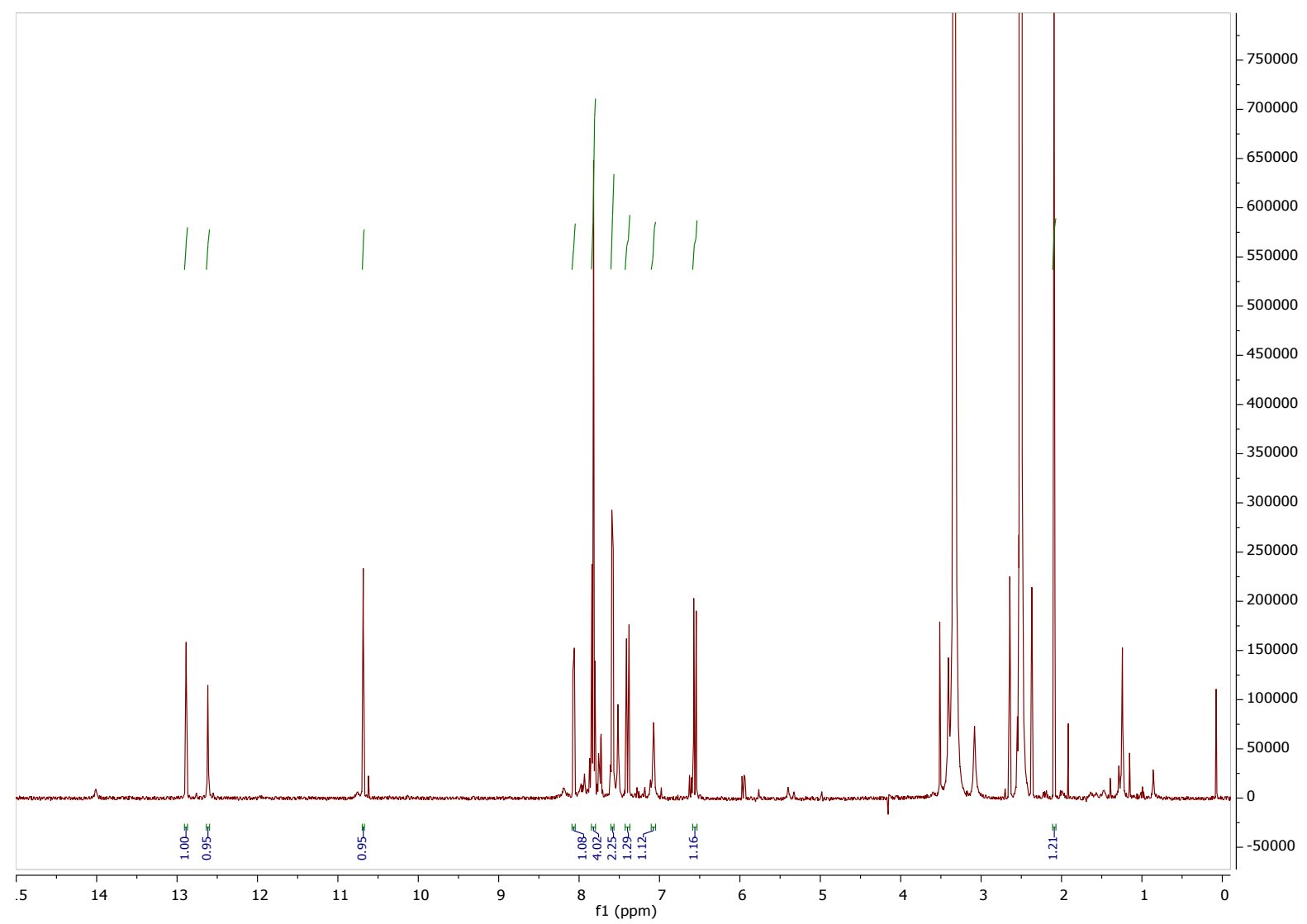

${ }^{1} \mathrm{H}$ NMR of NW1030 (500 MHz, DMSO-d6) 


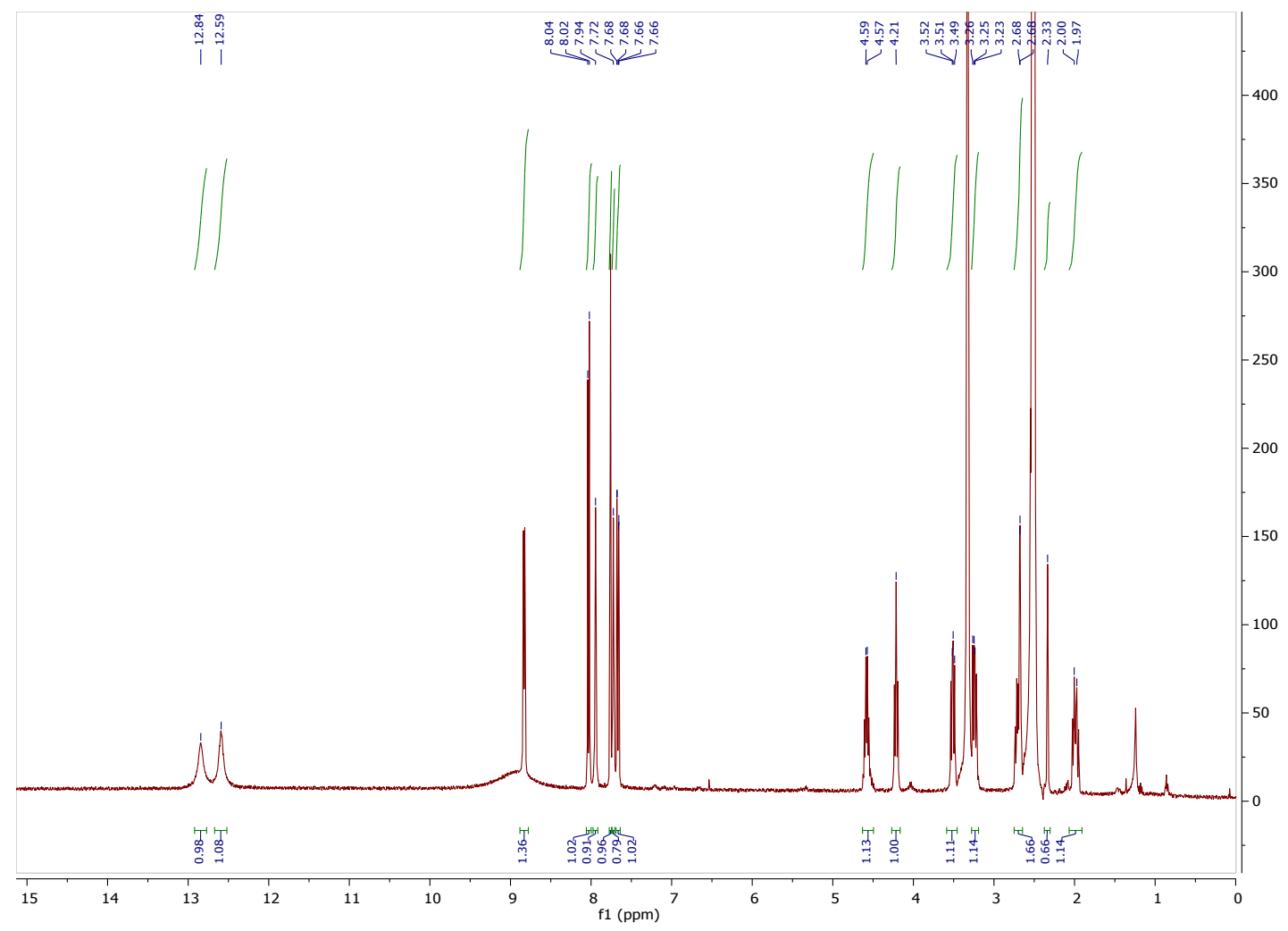

${ }^{1} \mathrm{H}$ NMR of NW1047 (500 MHz, DMSO-d6)

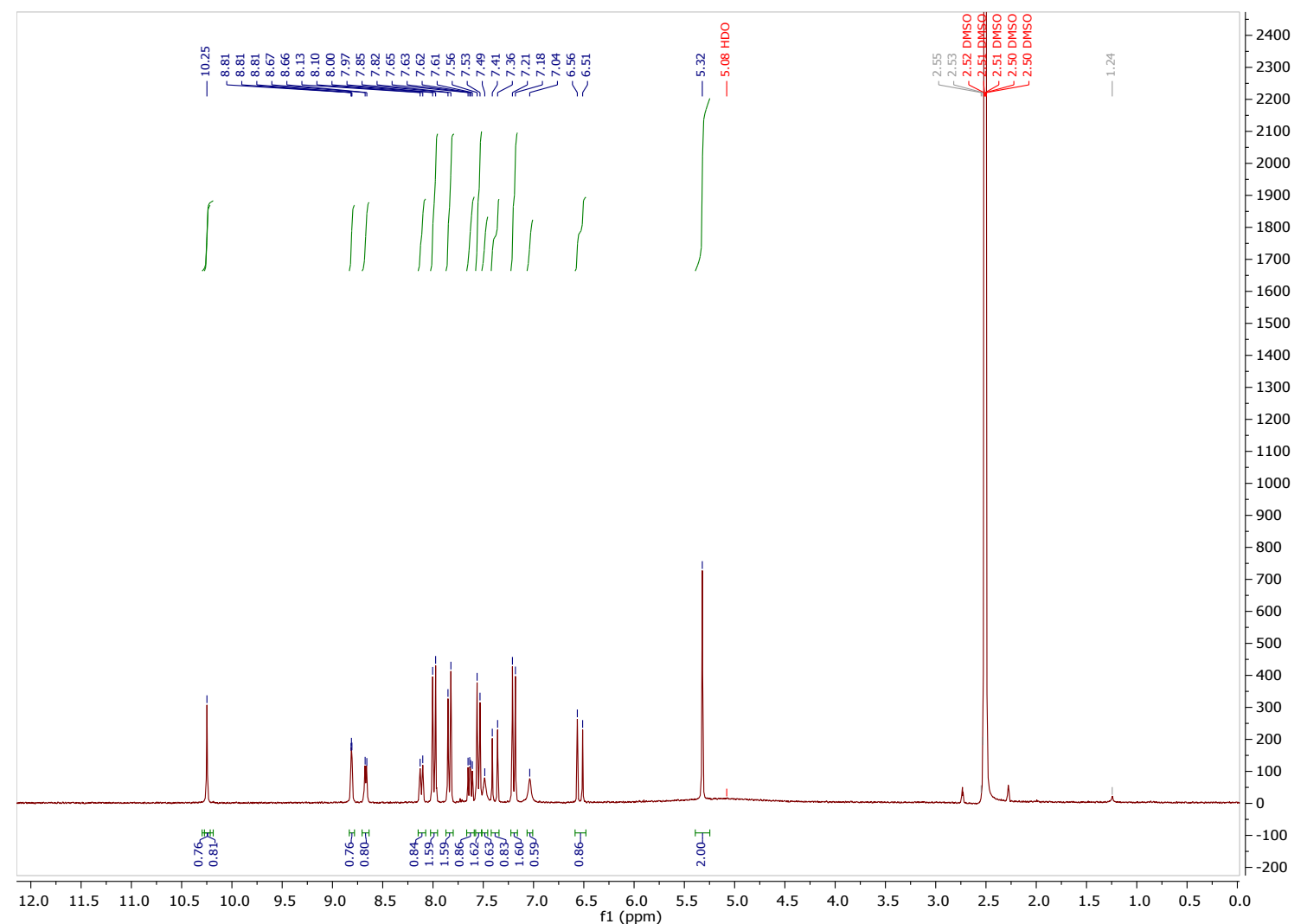

${ }^{1} \mathrm{H}$ NMR of NW1049 (500 MHz, DMSO-d6) 


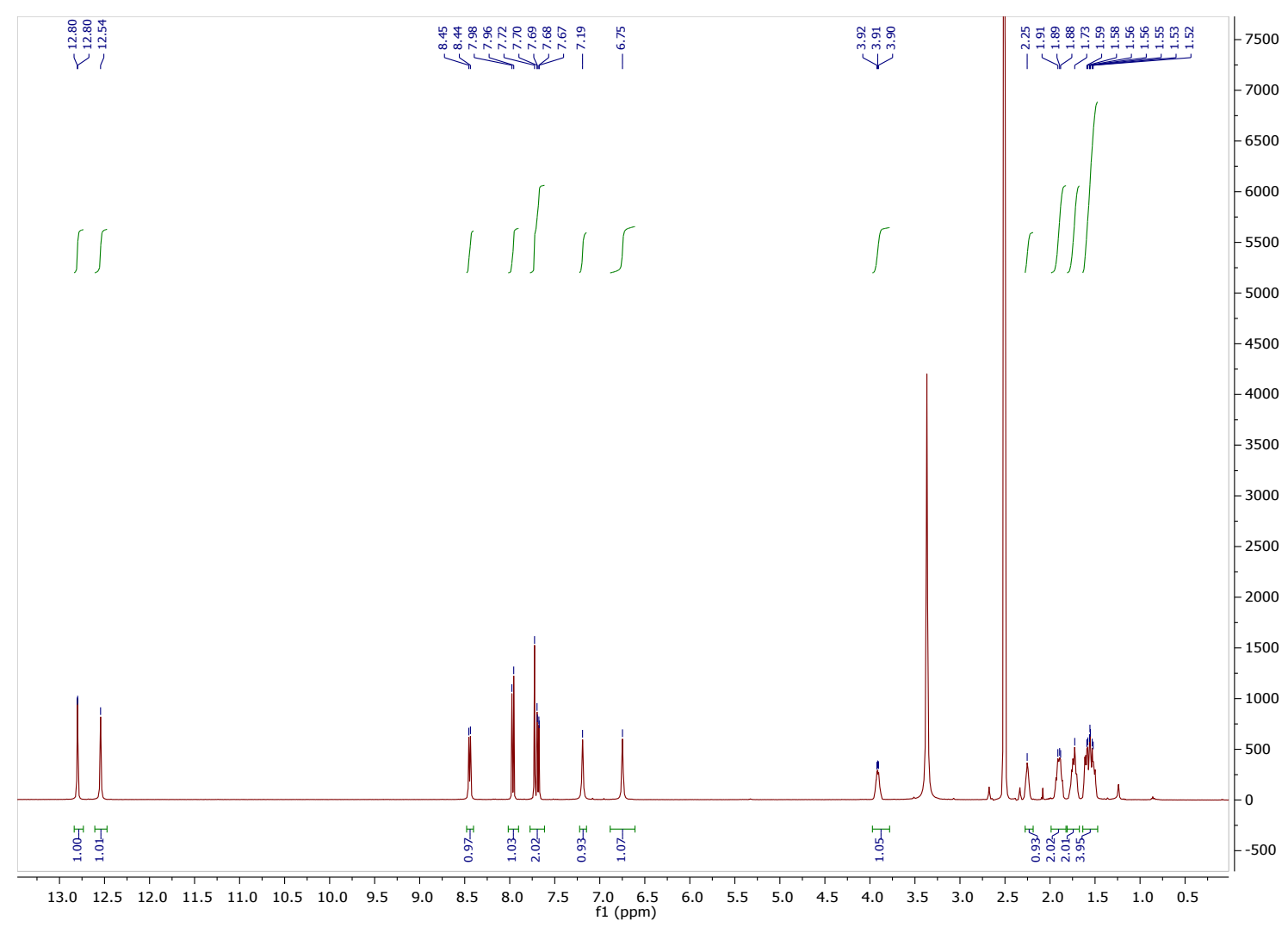

${ }^{1} \mathrm{H}$ NMR of NW1052 (500 MHz, DMSO-d6) 